\title{
«Para reintegrar la Nación». El Perú en la política negociadora del Trienio Liberal con los disidentes americanos, 1820-1824 ${ }^{1}$
}

por

\author{
Ascensión Martínez Riaza \\ Universidad Complutense Madrid
}

Durante el Trienio Liberal (1820-1823) el tratamiento de la cuestión americana tomó nuevos derroteros. La negociación con los disidentes fue la gran apuesta del segundo liberalismo para restaurar la unidad de la Nación española en un escenario de avance de la insurgencia. Desde la perspectiva de la política española se analiza cómo abordaron esta alternativa los poderes centrales. Se presenta el marco legislativo y su desarrollo y cuál fue la posición del Rey, el Gobierno, el Consejo de Estado y las Cortes. Se calibra su importancia en el contexto de las otras opciones que se barajaron, la solución militar y la mediación de Gran Bretaña. Se sigue la proyección del proceso negociador en América, con especial atención al Virreinato del Perú.

Palabras Clave: Trienio Liberal; política americana; negociación; legislación; Cortes; gobierno; Consejo Estado; escenario americano; Virreinato Perú.

\section{INTRODUCCIÓN}

Siguiendo las instrucciones de las instancias centrales, los virreyes del Perú, Joaquín de la Pezuela y José de la Serna, se dirigieron a José de San Martín para proponerle entablar negociaciones que restablecieran la unidad de la Nación española y evitaran la guerra. Las posiciones irreductibles de uno y otro lado condujeron a un fracaso que se reprodujo en otros escenarios ameri-

1 Este trabajo forma parte del Proyecto de Investigación I+D Tiempos de desconcierto. Politica y sociedad en la Independencia del Perú, 1820-1824, Referencia HAR2008-03256, financiado por el Ministerio de Ciencia e Innovación de España. Agradezco la ayuda de María Jesús Álvarez Coca y Evelia Vega González del Archivo Histórico Nacional de España y de Marta Ruiz Jiménez del Archivo del Congreso de los Diputados. 
canos. La historiografía sobre la independencia del Perú ha tratado la cuestión, con especial atención a las negociaciones de Miraflores y Punchauca ${ }^{2}$. Menos conocido es el proceso que llevó a ellas y que hay que situar en las coordenadas de las alternativas que se barajaron durante el Trienio Liberal (1820-1823) para enfrentar la pacificación americana ${ }^{3}$. No había vuelta atrás, las dinámicas independentistas y el desconocimiento, la impotencia y la atención prestada a asuntos más cercanos por parte de las autoridades peninsulares, convergerían en la separación definitiva, con excepción del Perú, de la totalidad de las provincias continentales.

Cuando el 7 de marzo de 1820 Fernando VII anunciaba su disposición a jurar la Constitución de $1812^{4}$ el gobierno español todavía era efectivo en los virreinatos de Nueva España y el Perú, mientras que en el de Santa Fe y la Capitanía general de Venezuela las armas dirimían la suerte de los bandos encontrados. Rompiendo su conocida voluntad de pacificar militarmente los territorios en insurgencia, y cuando todavía el restablecido orden liberal daba sus primeros pasos, Fernando VII giraba sobre sí mismo y abría la posibilidad de una alternativa negociada, la «conciliación». No se trataba de una decisión libre y deseada, su situación comprometida y vulnerable le obligaron a plegarse a las directrices de la Junta Provisional, el Gobierno y el Consejo de Estado y, no hay que olvidarlo, a la presión social y de los militares sublevados a raíz del levantamiento del teniente coronel Riego el primero de enero de $1820^{5}$.

La negociación fue la apuesta inicial del segundo liberalismo para revertir «decisiones erradas» y restaurar la integridad de la Monarquía. La filosofía que sustentaba este procedimiento político era que el retorno al sistema liberal y la reimplantación de la Constitución devolvería a las provincias americanas los derechos que el absolutismo les había enajenado y conjuraría el engaño en

2 Vargas Ugarte, 1929. Porras Barrenechea, 1950. Pons Muzzo, 1999. Puente Candamo, 2007: 59-67. Fisher, 2000; 2009.

3 Pacificación es la expresión genérica que aparece en la documentación para aludir a las medidas peninsulares. Los insurgentes son «disidentes», mientras los leales a la Corona son realistas, nacionales y españoles.

${ }^{4}$ La jura formal sería de 9 de marzo y el 9 de julio el Rey la revalidaría ante las Cortes, pero fue el día 7 de marzo cuando se produjo el anuncio y así lo publicaba la Gaceta Extraordinaria de Madrid, 31, 8 de marzo de 1820: 239. Por eso en los documentos de la vuelta al absolutismo el 7 de marzo es la fecha que aparece como parte aguas a partir de la cual se derogaban todas las normas y actuaciones del constitucionalismo.

5 Aun así Fernando VII nunca admitió la posibilidad de reconocer la independencia y miró siempre a las potencias absolutistas de la Santa Alianza esperando una intervención que tomaría cuerpo en abril de 1823 con la entrada de los Cien Mil Hijos de San Luis. Sánchez Mantero, 1981. Artola, 2008. 
que una minoría con intereses espurios tenía sumida a la población. Todos los intentos terminaron en fracaso, con singularidades regionales pero con un denominador común, la posición inamovible de las partes. Como punto de partida para llegar a posibles consensos los disidentes exigían el reconocimiento de la independencia y los españoles el acatamiento de la Constitución.

Con la jura de la Constitución de 1812 por Fernando VII comenzaba la segunda etapa de la monarquía constitucional en España, con una diferencia sustancial con relación al liberalismo doceañista, ahora el rey estaba presente y dispuesto a ejercer sus prerrogativas en una realidad diferente a la del primer liberalismo, tanto en su dimensión peninsular como en el escenario america$n^{6}$. La descoordinación y el conflicto entre los poderes centrales condicionaron la política del Trienio, también en lo relativo al tratamiento de la cuestión americana ${ }^{7}$. No hubo entendimiento entre el rey y los distintos gobiernos que se sucedieron, así como tampoco fue fácil la relación entre los secretarios de Despacho y las Cortes. Si bien Fernando VII ocuparía la cúspide del organigrama del poder, por R.D. de 9 de marzo se constituía una Junta Provisional, que se disolvería al comenzar a sesionar las Cortes el 9 de julio, y que tuvo amplias facultades, al punto de que su voluntad llegaría a prevalecer sobre la del monarca ${ }^{8}$.

La apertura de las Cortes reanudaba los mecanismos legislativos del liberalismo doceañista. Durante el Trienio estuvieron siempre reunidas, ya en legislaturas ordinarias-extraordinarias ya en Diputación Permanente, y entre las comisiones formadas para trabajar los distintos asuntos estuvo la de Ultramar'. Según la Constitución, el Rey y las Cortes participaban en la dirección política de la Nación, pero el procedimiento a seguir llevaba a la dilación y ralentización de la aplicación de las leyes ${ }^{10}$. El Consejo de Estado fue restablecido por iniciativa de la Junta Provisional el 18 de marzo de 1820 con los mismos

${ }^{6}$ El autor de referencia sigue siendo Gil Novales, 1980; 2010.

7 Para seguir la política de España hacia América en el Trienio, ver Robertson, 1926. Delgado, 1950. Hamnett, 1985. Anna, 1986. Costeloe, 1989. Jensen, 1996. Nater, 1996. Gil Novales, 1999. Broseta Perales, 2002; 2003. Frasquet, 2005; 2008b.

8 Buldain Jaca, 1982: 39-63; 1989: 133-158.

9 Los Diarios de Sesiones, así como las Actas Secretas y las sesiones de la Diputación Permanente están disponibles en la red. Se ha consultado la Fundación de Estudios Constitucionales 1812 http:/www.constitucion.org. Para la secuencia comparada de los gobiernos y las legislaturas, ver Gil Novales, 1980: 1-59. Medina, 2002.

10 En más de una ocasión el rey se saltó la vía establecida. A lo largo del Trienio Fernando VII sancionó 60 leyes siguiendo la mayoría de las veces las recomendaciones del Consejo de Estado. Para la relación entre el Monarca y las Cortes, Gómez Rivero, 2010. 
miembros que la componían cuando se volvió al absolutismo ${ }^{11}$. Ejercía funciones consultivas y de asesoramiento al monarca y llegó a tener una preeminencia tal que funcionó como un verdadero Consejo de Ministros. En la política americana asumió posiciones conservadoras llegando a aconsejar soluciones militares, siempre en el respeto a la Constitución. Sus dictámenes fueron piezas capitales para definir líneas de actuación y tomar decisiones que cristalizaron en reales órdenes y decretos de las Cortes, aunque no se comportó como un cuerpo uniforme y los votos particulares de los consejeros jalonaron sus actuaciones.

Con el telón de fondo del entramado de la organización del poder central y su funcionamiento, en el artículo se analiza el significado y alcance de la negociación en el marco de lo que fue la política americana del Trienio. Se propone la distinción de dos etapas en relación con la evolución de la dinámica peninsular y la extensión de la insurgencia en la América española. Se atiende al marco normativo, a cómo intervinieron en su desarrollo y concreción las instancias competentes y a cuál fue su proyección en el escenario americano. $\mathrm{Y}$ en estas coordenadas se introduce el tratamiento que se dio al Virreinato del Perú, en el que conciliación y solución militar fueron caras de la misma moneda.

\section{LA PACIFICACIÓN NEGOCIADA. CONCILIACIÓN O GUERRA}

Entre marzo y junio de 1820, antes de que se reunieran las Cortes, los poderes centrales pusieron en marcha la vía de la negociación, que ya no se abandonaría aunque se barajaran otras opciones como la pacificación militar y la mediación de Gran Bretaña, a cambio de beneficios comerciales. Las iniciativas terminaron en fracaso por una convergencia de razones que tienen que ver con la posición de fuerza de los interlocutores-disidentes, poco dispuestos a hacer concesiones, y con las dificultades de las autoridades españolas, tanto centrales como americanas, para implementar una política eficaz debido a la falta de recursos económicos y militares en un escenario que se tornaba progresivamente adverso.

11 Archivo Congreso Diputados, Madrid (ACD), Papeles Reservados de Fernando VII. Consejo de Estado, 13 de marzo de 1820. En el decreto de su constitución figuran Blake, Agar, Ciscar, arzobispo de Toledo, Andrés García, Garay, Castaños, Almansa, Cevallos, marqués de Piedrasblancas, Ibar, Ayciniena, Ranz Romanillos, Requena y Varea. 
El marco normativo y las instancias centrales: el Rey, la Junta Provisional, el Gobierno y el Consejo de Estado

Desde muy pronto las instancias centrales tomaron cartas en el asunto y conminaron al rey a manifestarse sobre la política americana, supervisando sus pasos para paliar veleidades autoritarias ${ }^{12}$. El 18 de marzo de 1820 el ministro de Ultramar comunicaba a la Junta Provisional que el rey deseaba saber su parecer acerca del modo en que debía anunciar a las provincias la jura de la Constitución y todos los demás sucesos, y el 24 de marzo la Junta respondía con cinco proposiciones que debían trasladarse al Consejo de Estado ${ }^{13}$.

Con la aquiescencia de la Junta, Fernando VII se dirigía a los habitantes de Ultramar en una Proclama de 31 de marzo que circuló ampliamente. El rey presentaba una forzada cara «constitucional» y esgrimiendo como argumento central las ventajas que les reportaba la jura de la Constitución, exhortaba a los «disidentes» a volver al seno de la Monarquía abandonando el camino de la guerra, ya que el sistema liberal les devolvía derechos y libertades. Les ofrecía el perdón e implementar los medios para que presentaran sus quejas, a las que se darían soluciones. Pero, en el caso de que desoyeran sus consejos y rechazaran la mano que se les tendía, advertía, «temed todos los males que producen los furores de una guerra civil». El mensaje rezumaba ese talante soberbio y de superioridad que él nunca abandonó, envuelto en un discurso paternalista que difícilmente podía ser bien recibido por los insurgentes a los que llamaba «extraviados de la senda del bien» ${ }^{14}$. El Consejo de Estado trataría la cuestión en sesión extraordinaria de 2 de abril de $1820^{15}$, y emitiría un dictamen considerando oportunas las cinco proposiciones de la Junta Provisional, y mostrándose partidario de la conciliación bajo «la obediencia de la Constitución de la Monarquía Española», aconsejaba prudencia. Era necesario remitir urgente-

12 Se han localizado proclamas de Fernando VII a Ultramar sin fecha, que fueron reprobadas por la «Junta de Ministros» debido a que justificaba el absolutismo de 1814 por la «carencia de datos y noticias» sobre lo ocurrido durante su ausencia y aducía que, a falta de los medios para la conciliación, había recurrido a la fuerza armada para reducir al orden aquellas provincias «alucinadas con una falsa sombra de libertad e independencia», Archivo General de Indias (AGI), Indiferente General 1568.

13 El Secretario de Ultramar al Presidente de la Junta Provisional, Palacio, 2 de julio de 1820, AGI, Indiferente General 1568.

${ }^{14}$ El Rey a los habitantes de Ultramar, Salmón. Sr. Secretario de Consejo de Estado, Palacio, 31 de marzo de 1820, AGI, Indiferente General 1568. Hay copias en diferentes repertorios españoles e hispanoamericanos y se trata de un documento ampliamente analizado por la investigación especializada.

15 Archivo Histórico Nacional (AHN), Estado, Actas del Consejo de Estado, Libro 22. 
mente a América todos los decretos expedidos por S.M. desde el 7 de marzo, proceder al cese inmediato de las hostilidades e instar a los disidentes a que juraran la Constitución y eligieran diputados a Cortes, y solo después habría una amnistía de olvido recíproco y absoluto ${ }^{16}$.

Fue la Real Orden de 11 de abril de 1820 en que su Majestad quiere que por todos los medios adaptables se acabe la guerra en las Américas, ya mediatizada por las indicaciones de la Junta Provisional y el Consejo de Estado, la que marcaría la pauta de lo que habría de ser la relación con los disidentes en la primera etapa negociadora. Encabezada por el secretario de Ultramar Antonio Porcel en nombre del Rey, como la Proclama, iba dirigida de manera personalizada a los virreyes y capitanes generales. La introducción desvelaba cómo se había gestado el cambio y qué instancias lo habían promovido:

Una de las primeras cosas que llamó la atención del Rey luego que adoptó y juró la Constitución política de la Monarquía publicada en Cádiz el 19 de marzo de 1812, fue el modo con que debía anunciarse a las Provincias de Ultramar tan señalado acontecimiento: y para hacerlo según exigen la elevada dignidad y carácter de su Majestad y las críticas circunstancias en que se hallan esos pueblos quiso oír el dictamen de la Junta Provisional de esta Corte y el del Consejo de Estado Constitucional, y de acuerdo con ambas Corporaciones se ha servido resolver...

Sobre estas bases, el rey daría todo por concluido, «publicando un absoluto olvido de lo pasado»; sin embargo se advertía a virreyes y capitanes generales que el margen de maniobra de que disponían terminaba en el punto en que fuera rechazada la oferta conciliadora, en cuyo caso la guerra continuaría, pero España habría demostrado ante Europa y todo el Universo su moderación ${ }^{17}$.

El 15 de abril estaban terminadas las Instrucciones reservadas para los Comisionados que van de orden del Rey a procurar la pacificación de las Provincias disidentes de Ultramar, elaboradas por el gobierno y complementadas por Ligeros apuntes en el expediente sobre remitir a las Provincias disidentes

16 Dictamen del Consejo de Estado, Palacio 5 de abril de 1820, AGI, Indiferente General 1568. Firmaban Joaquín Blake, el cardenal arzobispo de Toledo, Francisco Javier Castaños, el marqués de Piedrablanca, José Aycinena, Antonio Ranz Romanillos, Francisco Requena y Esteban Varea.

17 Real Orden de 11 de abril de 1820 por la que se dan instrucciones a virreyes y capitanes generales americanos para que se jure la Constitución, se elijan diputados a Cortes y se negocie con los insurgentes. Reales órdenes. Gobernación de Ultramar, AGI, Indiferente General 1568. Las copias añaden «y faculta al virrey o capitán general» según el caso. La remitida al virrey Pezuela está, entre otros, en la Colección Documental de la Independencia del Perú (CDIP), VI, Asuntos Militares, 3, 1971: 2-6, y se introduce en los análisis de la historiografía especializada, por ejemplo, Anna, 1986: 263-265. Laserna, 2010: 191-192. 
de Ultramar comisionados que tratan de restablecer la paz por medios conciliatorios. Las 51 instrucciones, en las que estaban implicados varios ministros, desarrollaban la R.O. de 11 de abril y atendían a cuestiones generales y específicas. Disponían que luego de recibir las últimas órdenes del ministro de Ultramar Porcel, los comisionados se dirigieran a su destino en América, donde presentarían sus nombramientos e instrucciones a los virreyes y capitanes generales que formarían y presidirían una Junta de Pacificación ${ }^{18}$. A las entrevistas con los gobiernos disidentes acudiría el comisionado regio en compañía de uno o más integrantes de la Junta, designados por el virrey o el capitán general. Para inspirar confianza se propondría el cese de hostilidades por mar y tierra. Era objetivo prioritario conseguir que se jurara la Constitución, para lo cual debía fomentarse su conocimiento. Se ofrecería a los disidentes no remover a «ninguno jefes o empleados actuales», y el que enviaran comisionados a España, como alternativa a la elección de diputados a Cortes, con las proposiciones que mejoraran la unión con la metrópoli. Si no entraban en razón, «se reanudarán las hostilidades, pero se procurará hacer la guerra con menos encarnizamiento». Se planteaba así la cuestión de la «guerra justa» que estaría presente desde entonces como argumento en las justificaciones de realistas y patriotas.

Varias de las instrucciones atendían a los términos de una cuestión central que gravitaría a lo largo de toda la política negociadora, la firma de acuerdos comerciales provisionales. Se disponía que se abriera la comunicación entre los países disidentes y con la Península, adoptando medidas proteccionistas para el intercambio entre la Metrópoli [sic] y las provincias leales; que se hiciera ver a los jefes de los disidentes que el comercio directo en buques extranjeros era perjudicial para ambas partes; y que se considerara la nacionalización de los buques extranjeros mediante el enarbolado de la bandera nacional y con una tripulación formada por dos tercios de españoles de ambos hemisferios y con capitán y sobrecargo españoles. En la esfera de lo social se encomendaba a los comisionados que concitaran el apoyo del pueblo recordándole el estado feliz de que antes gozaba, «cuando no había semejantes turbulencias» y apelaran a la influencia del clero regular y secular para que contribuyeran «al cambio de la opinión». Nunca debía admitirse la mediación extranjera, «porque nada hay más apolítico que llamar a un extraño para que se interponga de juez en los altercados domésticos, pues la historia de todos los siglos nos presenta tristes ejemplos de que siempre el tercero se apropió de aquello mismo que se litigaba». Y es más, debería negociarse que salieran poco a poco del país aque-

18 Las juntas de pacificación se constituyeron en Venezuela y el Perú. 
llos que no ejercieran un arte útil, y tendrían que cesar en sus funciones todos los agentes diplomáticos de cualquier potencia ${ }^{19}$.

Definido el marco normativo, el mecanismo de la negociación se ponía en marcha. El 16 de abril actuaban el Rey, el Gobierno y el Consejo de Estado y completaría el circuito la Junta Provisional. Fernando VII daba vía libre para el nombramiento de comisionados a Venezuela, Santa Fe, Buenos Aires, Chile y Lima ${ }^{20}$. Por su parte el Consejo de Estado en sesión extraordinaria emitía el dictamen que se le solicitaba en relación con las Instrucciones: indicaba que era preciso remover de sus puestos a las personas que se habían hecho odiosas «al partido disidente» para eliminar estorbos a la pacificación (se refería a los generales Sámano y Morillo que enfrentaban a Bolívar en Nueva Granada y Venezuela); las negociaciones no debían iniciarse ni en el Río de la Plata, ni en la Corte del Brasil, y en consecuencia los comisionados para pacificar el Río de la Plata irían a Lima a ponerse de acuerdo con el virrey del Perú; se recomendaba no precipitarse en lo relativo a la propuesta del rey de que agotados todos los medios se volviera al estado de guerra; se mostraba de acuerdo con que no se enviaran comisionados a Nueva España por su estado de tranquilidad, aunque sin bajar la guardia y manteniendo un seguimiento cercano. Sin embargo, aconsejaba que junto a los comisionados se enviaran fuerzas marítimas «que impongan y estén a la mira de lo que produzcan las negociaciones, protejan el comercio, y animen y sostengan a los patriotas $\rangle^{21}$.

El rey resolvió, oído el Consejo de Estado y la Junta Provisional, que fueran dos comisionados a Venezuela, Santa Fe, Buenos Aires por Río de Janeiro, y a Lima, con la misión de «facilitar la conciliación de aquellas provincias con la Madre Patria». Los elegidos debían ser militares honrados e instruidos que no fueran naturales de las provincias ni hubieran estado empleados ni prisioneros en ellas ${ }^{22}$. Así mismo pedía que todas las autoridades americanas recibieran las mismas órdenes para dar una imagen de uniformidad de criterios ${ }^{23}$. A

19 AGI, Indiferente General 1568. Hay un borrador manuscrito de las Instrucciones con claves para usar en correspondencia secreta y anotaciones al margen para que fueran singularizándose con nombres y lugares según los destinos.

20 Minuta de Ultramar, Palacio, 16 de abril de 1820, AGI, Ibidem.

21 Sesión extraordinaria de 16 de abril de 1820, AHN, Actas del Consejo de Estado, libro 22. Consejo de Estado, Palacio, 18 de abril de 1820, ACD, Papeles reservados de Fernando VII.

22 Antonio Porcel al secretario de Estado, Gobernación de Ultramar. Palacio 16 de abril de 1820, AGI, Estado 89. Pedía especial cuidado en el tratamiento del asunto del que dependía la tranquilidad de América y convocaba a los secretarios de Guerra y Marina para que aportaran sus indicaciones.

23 Exposición al Rey sobre la propuesta de los comisionados y gracias que se les han de 
su vez, la Junta Provisional, en clave conservadora, advertía al Gobierno del riesgo que podía acarrear el restablecimiento de la Constitución y de las instituciones representativas, porque el afianzamiento de los poderes locales y regionales podría tener como contrapartida el que se cuestionara la autoridad española e incluso que funcionarios reales cayeran en la tentación de asumir la autoridad por su cuenta ${ }^{24}$. La Junta siempre reivindicaría su papel supervisor y reclamaría el ser informada oficialmente de todos los pasos que se dieran en lo concerniente a un «encargo tan extraordinario» para la pacificación de América ${ }^{25}$.

\section{El escenario americano}

Serían los ministros de Estado, Guerra, y sobre todo los de Ultramar (Porcel) y de Marina (Jabat) del primer gobierno constitucional, los que se ocuparon del nombramiento de los comisionados y de perfilar lo concerniente a los sueldos y pormenores del viaje, con el concurso del gobernador de Cádiz, Cayetano Valdés, hombre fuerte del Trienio que propondría a los $\operatorname{candidatos}^{26}$. El 8 de junio de 1820 Porcel anunciaba:

Deseando el rey con la mayor eficacia que se acaben y extingan de una vez las turbulencias que de algunos años a esta parte agitan y destruyen varias provincias de la España ultramarina, ha contemplado necesario, entre otras cosas, el nombrar comisionados que pasen a los países que tienen la desgracia de padecer todos los horrores de la guerra civil, para que anuncien solemnemente las ideas benéficas que animan a SM de poner término a tantos males por vías suaves y conciliatorias, cual exige el nuevo sistema constitucional que cordialmente ha adoptado...

Los designados, mayoritariamente oficiales de la Marina, fueron: el brigadier José Sartorio y el capitán de fragata Francisco Espelius a Venezuela; el capitán de navío Tomás de Urrecha y el capitán de fragata Juan Barry a Santa Fe; el coronel Manuel Herrera, Tomás Comyn y el capitán de fragata Manuel Martín Mateo a Buenos Aires; el brigadier José Rodríguez Arias y el capitán de fragata Manuel Abreu a Chile; el capitán de navío Joaquín Goñi y el capi-

hacer con lo demás que fue acordado en Junta de ministros para que se realice este asunto, Gobernación de Ultramar, Palacio, 18 de abril de 1820, AGI, Indiferente General 1568.

24 El presidente de la Junta, Luis de Borbón, cardenal arzobispo de Toledo, al Rey y al secretario de Ultramar, Madrid, 19 de abril de 1820, AGI, Ibidem. Anna, 1986: 266-268.

25 Luis de Borbón, arzobispo de Toledo al Secretario de Ultramar, Madrid, 18 de junio de 1820, AGI, Ibidem.

${ }^{26}$ Minuta de Guerra a Ultramar, 7 de mayo de 1820, AGI, Ibidem. Para la trayectoria de Cayetano Valdés, Gil Novales, 2010: 3089-3090; ACD, Documentación electoral, 9, 1. 
tán de fragata Francisco Xavier Ulloa a Lima (con destino al Alto Perú). No se enviaban a Nueva España porque las provincias estaban pacificadas. Porcel aclaraba que era deseo del rey evitar posibles riesgos y azares y que por eso había designado a dos personas para cada misión, y añadía una minuta en que les informaba de su sueldo, medios de transporte, que se les otorgarían credenciales especiales y se les conferiría la distinción de comendadores de la Orden de Isabel la Católica ${ }^{27}$. Los sueldos variarían según la graduación (en el caso de los destinados a Chile y el Perú el capitán de navío Joaquín Goñi y el brigadier José Rodríguez Arias recibirían 500 reales al mes, mientras que los capitanes de fragata Francisco Xavier Ulloa y Manuel Abreu quedarían en 350 reales); para el transporte se alistaban en Cádiz la fragata de Guerra la «Viva» que trasladaría a los comisionados a Venezuela, Santa Fe, Chile y Lima, y el bergantín el «Aguila» a los que se dirigieran a Buenos Aires ${ }^{28}$.

A mediados de junio de 1820 los comisionados reunidos en Cádiz (todos menos Abreu), enterados de los términos de su encomienda, declinaban el nombramiento y así lo comunicaba Valdés a Jabat,

\begin{abstract}
... me han manifestado unánimemente que aunque conocen la honorífica distinción que se les hace designándoseles a una Comisión de tanta importancia, no se creen capaces de desempeñarla por considerarla de una superior elevación a su suficiencia y conocimientos y como sea de una naturaleza que no tiene analogía con su profesión, no se atreven de ningún modo a aceptarla... ${ }^{29}$.
\end{abstract}

Porcel lograría revertir la decisión introduciendo un elemento de flexibilidad al liberarles de la responsabilidad del éxito o fracaso de su misión. Solo los destinados al Perú se ratificaban en su renuncia: Goñi aducía razones económicas: necesitaba que se le adelantasen dos mil duros a cuenta de sus vencimientos y el pago de una asignación a su familia; Ulloa lo hacía porque tenía «tíos carnales» en aquellos países y gobiernos disidentes ${ }^{30}$.

Los comisionados destinados a Venezuela y Nueva Granada llegaron a Caracas en diciembre de 1820, donde supieron que Bolívar y Morillo habían firmado en Trujillo el 26 de noviembre un Armisticio y Tratado de Regularización de la Guerra entre España y Colombia, que era una de las tareas que se les había encomendado. De ahí que se concentraran en gestionar el envío de

27 Circular de Antonio Porcel, Madrid 9 de junio de 1820; y Gobernación de Ultramar, Madrid 11 de junio de 1820, AGI, Indiferente General 1568.

28 Se ha consultado un borrador sin fecha elaborado por Porcel, AGI, Ibidem.

29 Juan Jabat al secretario de Gobernación de Ultramar, Palacio, 22 de junio de 1820, AGI, Ibidem.

30 Juan Jabat al secretario de Gobernación de Ultramar, Palacio, 2 de julio de 1820, AGI, Ibidem. 
comisionados a la Península y en participar en las actuaciones de la Junta de Pacificación, hasta que comprobaron las nulas posibilidades de aplicar las Instrucciones por la intransigencia de Bolívar ${ }^{31}$.

Los nombrados al Río de la Plata se dirigirían a Río de Janeiro donde no lograron ser reconocidos como plenipotenciarios por la Corte portuguesa, a pesar de las gestiones del ministro español conde de Casa Flores. A mediados de noviembre llegaban a Montevideo desde donde mandaban una nota a las autoridades de Buenos Aires solicitando ser recibidos por la Junta de Representantes. Sin embargo, esta puso como condición el previo reconocimiento de la independencia con lo que el encuentro se frustró. Permanecieron dos meses en Río de Janeiro esperando que los cambios políticos derivados de la jura por Juan VI de la Constitución y su regreso a Portugal dejando a su hijo Pedro I al frente del Brasil propiciarían un nuevo acercamiento con los disidentes rioplatenses. Pero no fue así y se vieron obligados a comunicar al secretario de Ultramar que daban por concluida su misión y regresaban a la Península ${ }^{32}$.

En el Virreinato del Perú la política negociadora se tradujo en los encuentros que, a iniciativa de los virreyes Pezuela y La Serna y en cumplimiento de las órdenes peninsulares, se celebraron con San Martín en Miraflores y en Punchauca $^{33}$. El 4 de septiembre de 1820, seis meses después de que se produjera el cambio político en la Península, el virrey Pezuela recibía correspondencia que incluía la Proclama a los habitantes de Ultramar de 31 de marzo y la R.O. de 11 de abril de 1820. Dado que los comisionados designados para el Perú habían declinado el nombramiento, el 3 de julio de 1820 el secretario de Ultramar instruía a Pezuela para que nombrara a quienes debían negociar en el Alto Perú,

31 Correspondencia de los comisionados para la pacificación de Venezuela José Sartorio y Juan Barry, 1820-1823, AGI, Indiferente General 1571. Fernández, 1994: 23-39. Quintero, 2005: 432-444. Meza, 2007: 92-95. Lombardi, 2010: 194-212.

32 AGI, Buenos Aires 156. Indiferente General 1568. Roca, 2007: 481-483.

33 El trasfondo y desarrollo de las negociaciones en el Virreinato en Anna, 2003: 231-233. Fisher, 2000 y 2009. Puente Candamo, 2007: 59-67. Albi, 2009: 262-264 y 326-330. Laserna, 2010: 199-224. La documentación oficial fue editada de inmediato por los disidentes en Lima, Manifiesto de las sesiones tenidas en el pueblo de Miraflores para las transacciones intentadas con el general San Martín y documentos presentados por parte de los comisionados en ellas, se publican de orden de este gobierno, Lima, en la Casa de los Niños Expósitos, año de 1820, y Manifiesto y documentos de las negociaciones de Punchauca entre los diputados de los excmos. señores generales don José de San Martín y don José de la Serna a consecuencia de la llegada del capitán de fragata don Manuel Abreu, comisionado pacificador de la Corte de España, Lima independiente, Imprenta del Río, 1821. Una copia se encuentra en AGI, Lima 800 y están reproducidos en CDIP, XIII, Obra Gubernativa, 2, 1976: 1-50 y 55-139. 
... urgiendo mucho la necesidad de que se verifique este proyecto con la celeridad posible y no siendo posible hallar en el momento otras personas de las circunstancias que para ello se requiere; ha resuelto SM que enterado VE de todas las órdenes e instrucciones que llevan los comisionados que se dirigen a Chile, nombre en esa dos o más sujetos de su entera satisfacción y conocida reputación entre los disidentes que desempeñen esta misma comisión en las referidas provincias del Alto Perú con arreglo a lo que previenen los indicados papeles de que se les dará... y a las advertencias que se considere además ser preciso hacerles por la Junta que se ha de formar al intento en esa capital a la que podrán dar todas las noticias necesarias acerca del estado en que se halla la península los mencionados comisionados que van al Reino de Chile ${ }^{34}$.

Siguiendo las disposiciones de la península, Pezuela preparaba también conversaciones con los disidentes del Río de la Plata, y con ese fin encargaba al jefe militar del Alto Perú Juan Ramírez que se ocupara de lograr un armisticio con los gobernadores de Salta y Tucumán, aunque él se reservaba la resolución final. A tal fin nombraba a comisionados y les daba instrucciones «en cumplimiento de la Real Orden reservada en 11 de abril de este año para tratar con los gobiernos de las provincias del Río de la Plata sobre un advenimiento en que se aporten ó la pacificación definitiva de ellas, ó una suspensión de hostilidades en los términos que manifiestan los artículos siguientes» ${ }^{35}$.

El 11 de septiembre el virrey, tres días después del desembarco en Pisco de la Expedición Libertadora, proponía a San Martín el cese de las hostilidades y la firma de un armisticio, y tratar del cambio que auspiciaba el rey tras el restablecimiento de la Constitución adjuntándole copia de la Proclama de 31 de marzo y de la R.O. de 11 de abril $^{36}$. Simultáneamente comunicaba al ministro de Ultramar que se disponía a imprimir 1.000 ejemplares de la Constitución para remitirlos a todas las autoridades, y al conde de Casa Flores le pedía que trabajaran conjuntamente en la búsqueda de la paz por la conciliación ${ }^{37}$. A lo largo del proceso negociador Pezuela mantendría un doble discurso: se dirigía

34 Oficio de Ultramar al virrey del Perú (s/f, Porcel), Madrid, 3 de julio de 1820, AGI, Indiferente General 1568.

35 Excelentísimo señor general del ejército del Alto Perú don Juan Ramírez, Joaquín de la Pezuela, Lima, 5 de octubre de 1820, en Documentos del Archivo de San Martín, V, 1910-1911: 223-233. La documentación se encuentra en AGI, Buenos Aires 168-185 e Indiferente General 313 y 1570.

36 Pezuela, 1947: 758.

37 Oficio al excelentísimo ministro de Ultramar (por cifra) contestando a la Real Orden de 11 de abril en que manda se trate con los insurgentes a fin de conseguir la paz, Joaquín de la Pezuela, Lima, 11 de septiembre de 1820 y Oficio al señor conde de Casa Flores avisándole del contenido de la expresada Real Orden de 11 de abril, Joaquín de la Pezuela, excelentísimo señor conde de Casa Flores, Lima, 11 de septiembre de 1820, en CDIP, VI, Asuntos Militares, 3, 1971: 24-28. 
a San Martín desde la firmeza, ofreciéndole la conciliación, convencido de que cualquier mala paz era preferible a los desastres de la guerra, pero advirtiéndole de su resolución de hacer frente a cualquier agresión; mientras, en privado confesaba que las negociaciones eran inoportunas y que el «disidente» solo pretendía ganar tiempo ${ }^{38}$.

El mismo día de la jura de la Constitución en Lima (15 de septiembre), el Libertador aceptaba entrar en conversaciones en nombre del gobierno de Chile. Desde el 25 de septiembre al 5 de octubre los comisionados de ambos lados se encontraron en Miraflores, a las afueras de Lima. Las condiciones del virrey se resumían en que las tropas invasoras debían retirarse y San Martín avenirse a jurar la Constitución y acomodarse a lo que se establecía en la R.O. de 11 de abril. El Libertador proponía como solución de conveniencia el nombramiento de una comisión para buscar un príncipe de la familia real que se pusiera al frente de la monarquía del Perú independiente. Al vencer el 4 de octubre el armisticio firmado el 26 de septiembre, San Martín dio por rotas las negociaciones reanudándose las hostilidades con la ventaja que a los insurgentes les daba el haber podido reunir alimentos, caballos y hombres y conseguir adeptos entre la población de Lima ${ }^{39}$. Pezuela informaría al secretario de Gobernación de Ultramar el haber cumplido con lo encomendado y responsabilizaba a San Martín del fracaso advirtiendo que, contra lo que se pensaba en la Corte, los disidentes no tenían interés alguno por la reconciliación ${ }^{40}$. La llegada a Río de Janeiro de los comisionados nombrados para Buenos Aires y las presiones de las corporaciones de Lima llevarían a Pezuela a emprender un nuevo intento negociador y así lo hacía saber a San Martín el 14 de diciembre de 1820, pero la respuesta fue que no aceptaría a no ser «que V.E. se halle autorizado por las nuevas instrucciones de su gabinete para reconocer la independencia de los Estados de Chile y Buenos Aires y el establecer la del Perú» ${ }^{41}$. Pezuela pensó desde el principio que los enemigos no tenían otra intención que la de engañar para hacerse con el poder, y a posteriori concluiría que todas las buenas intenciones del rey y la Nación española para lograr la paz en América ha-

38 Pezuela, 1947: 772.

39 El mismo día en que terminaba el armisticio San Martín enviaba al general Álvarez de Arenales a la sierra central para controlar territorios y recursos agrícolas y mineros.

40 Oficio de Pezuela al Excmo. Sr. secretario de Estado y del Despacho de Ultramar, Lima, 19 de octubre de 1820, AGI, Indiferente General 313. Reproducido entre otros en CDIP, XII, Documentación Oficial Española, 2, 1972: 55-64, y VI, Asuntos Militares, 3, 1971: 138-141.

41 Oficio de San Martín a Joaquín de la Pezuela, 15 de diciembre de 1820, AGI, Lima 800. 
bían sido despreciadas «del modo más altanero y petulante por los mandones de los desgraciados países levantados en esta y la otra América ${ }^{42}$.

A tiempo pasado, cuando la situación política y militar del Perú se había alterado y Pezuela ya no estaba al frente del Virreinato, el ministro de Ultramar le escribía en nombre del rey alabando sus diligencias «para transigir pacíficamente con el disidente San Martín cumpliendo con lo que a V.E. se prevenía en la R.O. de 11 de abril del año próximo pasado, y S.M. me encarga que diga a V.E., como lo egecuto, que merecen su real aprobación las medidas adoptadas por V.E. $\rangle^{43}$. El 29 de enero de 1821 en Aznapuquio, el lugar donde estaba acampado el ejército, 19 oficiales disconformes con la política económica y la gestión militar del virrey, incluido el modo en que había conducido las negociaciones de Miraflores, forzaban su dimisión y entregaban el mando al general José de la Serna.

El nuevo Jefe Político Superior (acepción constitucional del virrey) daría cumplimiento a las órdenes de la Península aunque interferían en sus planes y no confiaba en que después de Miraflores San Martín estuviera dispuesto a hacer concesiones ${ }^{44}$. El curso de los acontecimientos le reafirmaba en que, además de la conciliación, era imprescindible el envío por España de refuerzos navales si quería mantener las provincias de Ultramar. Cuando, siguiendo el plan previsto y acordado con los altos oficiales, se disponía a abandonar Lima, supo de la llegada a Portobelo de los comisionados Manuel Abreu y José Rodríguez Arias (que abandonaría la misión por motivos de salud) ${ }^{45}$. Conocedor de que San Martín estaba cercando Lima, el Comisionado Regio Abreu cambió sus planes y en lugar de ir a Chile decidió entrevistarse con «aquel superior jefe», antes de encontrarse con el virrey, y así lo hizo el 27 de marzo con el consiguiente malestar de La Serna ${ }^{46}$. Las interferencias entre La Serna y Abreu recorrieron las negociaciones, que siguieron el protocolo de las Instrucciones de 15 de abril de 1820, y se desarrollaron en Punchauca, Miraflores y la

42 Pezuela, 1947: 759-760.

43 El secretario de Gobernación de Ultramar Ramón López Peregrín, Madrid, 22 de junio de 1821, AGI, Indiferente General 313. Hacía cinco meses que Pezuela había sido depuesto.

44 En la correspondencia al ministro de la Guerra, La Serna mostraba su escepticismo hacia la esperanza de Abreu de firmar un armisticio semejante al que habían sellado Morillo y Bolívar en la Costa Firme porque conocía el carácter de San Martín y «sus secuaces» y porque los habitantes estaban «por la novedad de la independencia», Del general La Serna al Ministro de Guerra, Lima, 8 de abril de 1821, en Torata, III doble, 1896: 256-257.

45 Buena parte de la documentación oficial de las negociaciones se encuentra en AGI, Lima 800, incluido el Diario político de Abreu editado por Fisher, 2009.

46 Manuel Abreu al alcalde de Huanvacho [sic], Ensenada de Samanco, 16 de marzo de 1821, AGI, Lima 800. 
fragata neutral «Cleopatra» desde comienzos de mayo hasta después del abandono de Lima por La Serna el 6 de julio de 1821. Ambas partes nombraron sus comisionados que se presentaron con las correspondientes instrucciones. Las de los españoles constaban de 13 artículos (que sufrirían modificaciones) articulados sobre la base de la firma de un armisticio entre tanto se llegaba a un consenso, la delimitación de las posiciones de ambos ejércitos y los términos para la apertura de comunicaciones y del comercio entre Chile y el Virreinato del Perúu ${ }^{47}$. Por su parte los comisionados de San Martín tenían el encargo de tratar un arreglo sobre el principio inmutable del reconocimiento de la independencia y la no aceptación de la Constitución como vínculo de unión. En el curso de las conversaciones San Martín mostraría de nuevo su opción favorable a la instauración de una monarquía y propuso la formación de una Regencia presidida por La Serna y dos delegados más nombrados por el virrey y por él mismo, mientras se encontraba a un infante que sería investido como Rey. El armisticio se firmaba el 23 de mayo y se ampliaría el 12 de junio, y en ese intervalo, el 2 de junio, se encontrarían La Serna y San Martín. A lo largo del proceso la posición de los altos oficiales españoles fue contundente en el sentido de no negociar con la independencia en juego, mientras que los comisionados de San Martín se mostraron firmes en que su reconocimiento era el paso previo para pensar en un acuerdo. Para el 9 de junio los puentes estaban rotos aunque el armisticio se prolongaba para permitir el abastecimiento de la Lima sitiada (que ambas partes interpretarían como un logro propio). Sería La Serna el que movería ficha anunciando la salida de Lima rumbo a la sierra y la disolución de la Junta de Pacificación ${ }^{48}$. Durante un tiempo Abreu y miembros de la Junta continuarían las conversaciones hasta que aislado y dejado a su suerte por el virrey, con el que mantendría una lacónica correspondencia, el Comisionado solicitaría a La Serna pasaporte para volver a España ${ }^{49}$, no sin dar cuenta de lo que había sido su cometido, que avalaba documentalmente ${ }^{50}$. El rey confirmaba en marzo de 1822 que, a través de una carta enviada por Abreu el 6 de noviembre de 1821, había conocido que no habían tenido resultados sus esfuerzos «paternales» de poner fin por la conciliación a los males de la guerra que afligían a esas provincias, y había resuelto dar por concluida la Comisión de pacificación y pedir al Comisionado que regresara a la Península ${ }^{51}$.

47 Lima, 30 de abril de 1821, AGI, Ibidem.

48 La Serna a la Junta de Pacificación, Lima, 6 de julio de 1821, AGI, Ibidem.

49 Oficio de Abreu a La Serna, Lima, 26 de octubre de 1821, AGI, Ibidem.

50 Manuel Abreu comisionado por el Gobierno de España para pacificar el Perú dando cuenta de sus negociaciones con los disidentes y acompañando documentos (manuscritos e impresos), Lima, 6 de noviembre de 1821, AGI, Ibidem, cit. Torres Lanzas, 1912, V: 374.

51 Aranjuez, 31 de marzo de 1822, AGI, Lima 800. 
La negociación a debate. Las Cortes y la posición del Gobierno. El Consejo de Estado y la pacificación militar

En el intervalo comprendido entre la salida de los comisionados a sus destinos americanos y la constancia del fracaso generalizado de la iniciativa negociadora las Cortes entraban en escena. Desde la apertura de las sesiones el 9 de julio de 1820 los diputados debatirían las alternativas sobre la pacificación, la Comisión de Ultramar y el Consejo de Estado presentarían sus informes y dictámenes y los secretarios de Despacho harían balance anual de lo concerniente a sus ministerios. Después de aprobar el 27 de septiembre de 1820 un decreto anunciando formalmente a las provincias de Ultramar el restablecimiento del sistema constitucional y ofreciendo perdón a los territorios disidentes que lo acataran ${ }^{52}$, las Cortes se concentrarían en asuntos de distinta índole relacionados con la realidad peninsular y el gobierno político-económico de las provin$\operatorname{cias}^{53}$. Las preocupaciones ultramarinas fueron introducidas por los representantes americanos, con los novohispanos a la cabeza ${ }^{54}$. Ante el silencio de los cinco diputados suplentes por Lima, el representante por Buenos Aires, Francisco Magariños, tomaba la palabra en la sesión de 30 de marzo de 1821 para hacer un dramático diagnóstico sobre lo que estaba sucediendo en el Perú, de tal gravedad que requería una respuesta firme de las Cortes. Su opinión era que la única posibilidad de conservar aquellas provincias era el envío de dos navíos de guerra que se unieran a los que había en el Callao (no sabía el diputado que para entonces no había banderas españolas ondeando en el Pacífico porque los escasos buques nacionales habían sido apresados y ya formaban parte de la flota insurgente). Para apoyar sus argumentos daba lectura a una carta, cuyo autor prefería dejar en el anonimato, en la que se daba cuenta del fracaso de las negociaciones que habían mantenido los diputados del virrey y los disidentes liderados por San Martín, que habían avanzado hasta cercar

52 Decreto XXXVII de 27 de septiembre de 1820 concediendo un olvido general de lo sucedido en las provincias de Ultramar en los términos que se expresa. Firmado, conde de Toreno, Colección de Decretos y órdenes generales de la primera legislatura de las Cortes ordinarias de 1820 y 1821, desde el 6 de julio hasta el 9 de noviembre de 1820, 1821, VI: 143-144.

53 Las Cortes debatirían a lo largo de las legislaturas reformas a introducir en el decreto sobre el Gobierno económico-político de las Provincias de Ultramar que se había promulgado el 23 de junio de 1813 y que se concretaría en la Ley para el Gobierno Económico y Político de las provincias de 3 de febrero de 1823. El debate sobre su regulación se prolongaría hasta agosto de 1823 en que razones de fuerza mayor lo dejaron en suspenso, Martínez Riaza, 1992: 658. La cuestión financiera ha sido trabajada por Haro, 2006.

54 El entramado del funcionamiento de las Cortes del Trienio y la participación novohispana en Frasquet, 2005: 123-158; 2008 b. 
Lima. La población civil y los militares se estaban planteando la conveniencia de que Pezuela fuera relevado del mando ${ }^{55}$.

Ya con noticias confirmadas sobre la inviabilidad de la conciliación, mediado el año de 1821, la posibilidad del reconocimiento de la independencia tomaba cuerpo en las Cortes en una doble línea: la auspiciada por los diputados que consideraban que había que aceptarla allí donde era una realidad, y la de quienes iban más allá y la defendían como un derecho inherente de los pueblos. Fue entonces cuando los novohispanos jugaron sus cartas proponiendo en la sesión de 25 de junio el conocido plan de confederación de España y Ultramar ${ }^{56}$. La iniciativa pasaría a la Comisión de Ultramar y ahí quedaría ante la inminente disolución de las Cortes. En el discurso de clausura de 30 de junio el rey ponía el puño sobre la mesa dejando claro que la única alternativa que admitía era la restauración de la unidad de la Monarquía.

La voz de las provincias continentales de Ultramar se reduciría a finales de septiembre de 1821, al aprobarse una moción que dejaba a los diputados suplentes fuera de la Cámara ${ }^{57}$. El 7 de noviembre el Consejo de Estado evacuaba, a petición del Gobierno, una Consulta sobre cómo conservar la integridad de la monarquía en la que se manifestaba partidario de la pacificación armada aunque compatible con la línea liberal de promocionar el envío de diputados a Cortes y la apertura del comercio en condiciones favorables. En ningún caso debería consentirse la desmembración de la Monarquía y recomendaba el envío de una fuerza naval al Pacífico para reforzar al Callao y otra a Veracruz, pero no aconsejaba la remesa de fuerzas terrestres que retardarían la expedición naval. Si no era posible reunir los fondos necesarios para levantarlas, el Consejo entendía que se podía acudir a la cooperación de Inglaterra a cambio de ciertas ventajas comerciales. Como en otras ocasiones no hubo unanimidad entre los treinta y tres consejeros y se añadieron votos particulares partidarios de la conciliación ${ }^{58}$. El pronunciamiento del Consejo de Estado a favor de una

55 Se refería a las negociaciones de Miraflores y a Aznapuquio, Diarios de Sesiones de las Cortes (DSC), 30 de marzo de 1821: 771-773.

56 No fue suscrito por los suplentes de Buenos Aires, Santa Fe y Chile, pero sí por los peruanos Miguel de Lastarria y Nicolás Fernández de Piérola, DSC, 25 de junio de 1821: 2472-2476. La propuesta ha sido tratada por Rodríguez, 1982: 304-306. Sánchez Andrés, 1997: 459-462; 2003: 27-29. Frasquet, 2005: 140-144; 2008a: 68-75.

57 La Segunda Junta Preparatoria lo aprobó con la salvedad de los cinco del Perú debido a las circunstancias excepcionales del asedio de San Martín que no permitía que los propietarios pudieran viajar a la Corte, DSC, 23 de septiembre de 1821: 7-21.

58 Consulta del Consejo de Estado sobre las provincias de Ultramar, reflexiones sobre su conservación y expediciones contra los insurgentes de ellas, Madrid, 7 de noviembre de 1821, Archivo del Museo Naval de Madrid (AMN), Colección Guillén, ms. 1206, 15, cit. Cuesta Do- 
vía armada, siempre «en la observancia a la Constitución», era una llamada de alerta que reavivaría la atención sobre la cuestión americana y sería el inicio de los planteamientos partidarios de la política de la negociación. La Consulta se trasladaría al rey y al Gobierno, que el 17 de enero de 1822 enviarían su respuesta a las Cortes. En el Informe del Gobierno a las Cortes sobre medidas de pacificación para las Provincias de Ultramar se convenía que no era oportuno reconocer la independencia, pero sí debería acordarse la suspensión de hostilidades durante dos años, tiempo suficiente para recibir y tratar las quejas de los disidentes; las provincias podrían autorizar a sus representantes en las Cortes que propusieran la suspensión de aquellos artículos de la Constitución que consideraran hostiles; se podría pensar en suspender ciertas reformas y agilizar el comercio interregional, permitiendo que pudieran comerciar con las Indias durante seis años potencias europeas con las que hubiera buenas relaciones; y para facilitar la pacificación sería conveniente acudir a la mediación de un país amigo $^{59}$.

Y en esa encrucijada, en la sesión de 25 de enero de 1822, el diputado por Extremadura Francisco Fernández Golfín leía la Memoria sobre el Estado Actual de las Américas y medio de pacificarlas redactada por el militar Miguel Cabrera de Nevares supuestamente por encargo del ministro de Ultramar Ramón López Pelegrín. Era un alegato a favor de que se respetara la voluntad de los americanos a ser independientes. Sobre las negociaciones, recordaba que los diputados «realistas» enviados a tratar la pacificación, o no fueron admitidos o en las reuniones con los disidentes no lograron ningún acomodamiento. Era inútil, entendía, divagar con diputaciones que no estuvieran plenamente autorizadas para tratar la independencia como se había probado en el Alto Perú, Buenos Aires y Costa Firme. Fernández Golfín añadía que dado que la Comisión de Ultramar era favorable al envío de comisionados, y que eso suponía un reconocimiento tácito de la separación, estos deberían contar con soporte legal que les diera legitimidad ${ }^{60}$.

Ante las Cortes llevaron la voz y posición del Gobierno los que fueron máximos responsables de la política americana, los secretarios de Despacho de Ultramar, de Guerra y de Marina, que además de intervenir en las sesiones tenían la obligación de presentar una memoria sobre su gestión. Dentro de lo

mingo, 1977: 254-257. Copia en AGI, Indiferente General 1569. Para Anna se trataba de la más inteligente posdata de un Imperio que se hubiera escrito (1986: 294).

59 Palacio, 17 de enero de 1822. AGI, Indiferente General 1571. Robertson, 1926: 28. Anna, 1986: 300-301.

60 DSC, 27 de enero de 1822: 2022-2027, copia en AGI, Indiferente General 1569. La Memoria fue editada en Madrid, Imprenta D. José del Collado, 1821. 
que se podía esperar de un discurso oficial que debía transmitir que la situación estaba bajo control, se observa un cambio entre las comparecencias de 1820 y 1821, que justificaban y avalaban los términos de la negociación en marcha, y las de 1822 en las que los secretarios no podían sino admitir que la conciliación había fracasado y la insurgencia se había extendido por las provincias continentales, de ahí que plantearan la necesidad de conseguir recursos militares y enviarlos a Ultramar. Hay que tener en cuenta que las Memorias eran anacrónicas porque se referían a tiempo pasado y no a lo que estaba sucediendo en el momento de las intervenciones, en ese sentido las tres responden a la primera fase de la negociación.

Haciendo balance de las Memorias de los secretarios de Ultramar se advierte que, en relación a otras regiones y a su importancia relativa por ser el último centro de poder español, el Virreinato del Perú fue hasta 1822 el gran desconocido debido a que la distancia y el curso de la insurgencia hacían que las noticias se recibieran con retraso y, según los ministros, casi nunca estaban contrastadas. La llegada en octubre de 1821 de los enviados de La Serna, el marqués de Valle-Umbroso y Antonio Seoane, para informar sobre el estado del Virreinato y justificar el golpe de Aznapuquio proporcionó información de primera mano ${ }^{61}$. En el caso de Nueva España la tranquilidad de 1820 que motivó que no fueran enviados comisionados se vio trastocada por el Plan de Iguala de 24 de febrero de 1821, en el que las elites criollas declaraban la independencia en el marco de una monarquía, y los Tratados de Córdoba de 24 de agosto de 1821, que daban vía libre al Imperio. Los ministros lo entendieron como una traición de los militares «nacionales» Iturbide y O'Donojú que propiciaron con su comportamiento el camino a la separación. El mapa complejo y cambiante de Venezuela y Nueva Granada preocupaba especialmente porque los disidentes tenían cada vez más capacidad operativa y las negociaciones, que eran conducidas con celo y moderación por los comisionados, eran rotas recurrentemente por Bolívar. Sobre el Río de la Plata, coincidían en que las guerras civiles que la asolaban eran un ejemplo de las funestas consecuencias de la independencia.

En cuanto a los secretarios de Guerra y de Marina, trataron la cuestión en el marco de los asuntos más generales que competían a sus ministerios. En las Memorias compartían pesimismo ante la debilidad de España, un país sin recursos militares y sin medios para levantarlos, y coincidían en que si no se producía un cambio radical lo que quedaba de América se perdería.

61 Puente Candamo, 1954. Los documentos de referencia están en AGI, Indiferente General 313. 
El primer secretario de Ultramar Antonio Porcel apenas tuvo tiempo para recabar información ${ }^{62}$. En su comparecencia se limitó a resumir la Proclama de 31 de marzo y la R.O. de 11 de abril y a publicitar la preocupación del rey por «reunir los ánimos de todos sus súbditos en ambos hemisferios, de aquietarlos y atraerlos hacia el nuevo gobierno paternal y justo que había adoptado». Para promover el acercamiento había dispuesto el envío de comisionados,

con amplias instrucciones para que en su nombre acuerden, interinamente y hasta resolución de las Cortes, lo que juzguen más conveniente al bien general del Estado y a su mayor lustre y gloria, bajo la inalterable base de la indivisibilidad y unión con la metrópoli ${ }^{63}$.

Porcel consideraba que las Cortes debían anteponer la pacificación de la España ultramarina a otros asuntos y como promotor de la vía de la negociación desmentía que el gobierno hubiera decidido el envío de fuerzas marítimas y aprestos militares.

El 4 de marzo de 1821 se producía un cambio de gobierno y serían los ya ex secretarios los que responderían de lo que había sido su pasada gestión ya que era preceptivo que los ministros no dejaran su cargo hasta no haber leído la Memoria. El responsable de Ultramar Ramón Gil de la Cuadra ${ }^{64}$ introducía muy de soslayo la negociación de Miraflores sobre la que solo disponía de noticias de «particulares» según las cuales el Jefe superior de Lima había propuesto al disidente San Martín un armisticio en virtud de las reales órdenes que acababa de recibir (se refería a la R.O. de 11 de abril de 1820) para que cesasen las hostilidades y se procediese a la reconciliación:

Por desgracia el jefe expedicionario, aunque accedió a una suspensión de armas en corto tiempo, no se avino a jurar la Constitución o a enviar diputados cerca de S.M para que presentasen sus solicitudes, que eran las bases esenciales de los convenios que propuso el virrey, quedando mientras llegasen las resoluciones de la Corte evacuado el Perú por las tropas chilenas ${ }^{65}$.

62 Memoria leida a las Cortes por el Sr. Secretario del Despacho de la Gobernación de Ultramar en la sesión del 12 de julio de 1820, DSC, 12 de julio de 1820: 55-59. Porcel firmaba la Memoria el 11 de julio de 1821. Analizan sus contenidos Jensen, 1996: 60-67. Broseta Perales, 2002: 81-90. Para la trayectoria de Porcel, Gil Novales, 2010: 2449.

63 Memoria, Porcel, DSC, 12 de julio de 1820: 55.

64 Memoria leida por el Sr. Secretario de Estado y del Despacho de la Gobernación de Ultramar ante las Cortes el 6 de marzo de 1821. DSC, 6 de marzo de 1821: 121-134. Para la trayectoria de Gil de la Cuadra, Gil Novales, 2010: 1300-1301. ACD, Documentación electoral, 8,19 .

65 Memoria, Gil de la Cuadra, DSC, 6 de marzo de 1821: 132. 
Más explícito era sobre el curso de las negociaciones en Venezuela, donde Morillo había comunicado en julio de 1820 al «jefe disidente» (se refería a Bolívar) que contaba con órdenes expresas del rey para suspender las hostilidades y tratar la conciliación, pero este exigió la «condición inadmisible» de reconocer la independencia, «lo cual era enteramente contra el espíritu de las órdenes que el rey tenía dadas, puesto que se prevenía en ellas, como base de toda transacción política, el reconocer y jurar la Constitución de la Monarquía, o enviar diputados cerca de su Real persona que hiciesen presentes los agravios de que se quejaban». El rey había visto con «mucho desconsuelo» la pertinacia de aquellos «extraviados españoles» y adoptado una doble resolución: que saliera desde Cádiz la división de Marina que desde hacía meses estaba destinada a Puerto Cabello, y que los comisionados renovasen las ofertas de paz. Poco tiempo después, el 21 de septiembre, era el «jefe disidente» el que ofrecía a Morillo entrar en negociaciones, y en consecuencia los comisionados de Caracas salieron al lugar acordado, pero los disidentes no solo no se presentaron sino que amenazaron con atacar la ciudad española de Maracaibo. El gobierno estaba a la espera de recibir la correspondencia de Morillo con las explicaciones necesarias y Gil de la Cuadra reiteraba que nunca se habían abandonado las esperanzas de que «se extingan las funestas rivalidades por diferencias insignificantes y pueriles» y que todos se trataran como lo que eran, hermanos, miembros de una sola familia ${ }^{66}$.

Juan Jabat, desde el Despacho de Marina, daba la medida de las cosas explicando que la Armada se encontraba en estado ruinoso y que no se había recibido sino una pequeña cantidad del presupuesto asignado a su Secretaría. Aún así, el 11 de noviembre de 1820 se había podido fletar a Puerto Cabello una división que había arribado cuando ya había concluido el armisticio entre los disidentes y el ejército nacional. El foco de la mayor preocupación estaba en el Callao, que había que reforzar a toda costa hasta lograr «la superioridad marítima, de que tanto ha menester, y sin la cual corren peligro tarde o temprano, a pesar de los heroicos esfuerzos de los ejércitos, tan extensos, ricos y poderosos dominios del imperio español» ${ }^{67}$. En noviembre de 1820, Jabat notificaba al secretario de Ultramar que había despachado con el rey para exponerle las condiciones del envío de fuerzas navales al Callao para lo que contaba con apoyo de comerciantes de Cádiz ${ }^{68}$.

66 Memoria, Gil de la Cuadra, DSC, 6 de marzo de 1821: 134.

67 Memoria leida a las Cortes por el Sr. Secretario de Estado y del Despacho de la Secretaría de Marina, DSC, 11 de marzo de 1821: 417-418. Para la trayectoria de Jabat, Gil Novales, 2010: 1557-1558.

68 Juan Jabat al Secretario de Ultramar, 4 y 5 de noviembre de 1820, AGI, Indiferente General 1568. 
A finales de 1821 el Rey, el Gobierno y el Consejo de Estado consideraban seriamente la pacificación militar. La Consulta del Consejo de Estado de 7 de noviembre había desencadenado un debate a varias bandas y sería en las Cortes donde, a partir de la experiencia adquirida y de los cambios acelerados que se producían en América, se replantearía la posibilidad de relanzar la vía de la negociación. El resultado serían los decretos de las Cortes de 13 de febrero y 28 de junio de 1822. El camino no estuvo exento de polémica y desacuerdos en un clima político crecientemente polarizado. En el intervalo entre uno y otro decreto se producía la transición del dominio de los liberales moderados a los exaltados que se hacían con el control del legislativo en febrero y del gobierno en agosto, tras ser abortado el 7 de julio el golpe de Estado preparado por Fernando VII para poner fin a la experiencia constitucional ${ }^{69}$.

El decreto de 13 de febrero se aprobaba al final de la última legislatura moderada y cuando todavía se sentaban en las Cortes diputados de las provincias continentales de Ultramar, el de 28 de junio era debatido en una Cámara de mayoría exaltada y con la presencia de solo un diputado continental, el guatemalteco Ibarra ${ }^{70}$. La alternativa de la negociación no encontraría en las elites políticas peninsulares la cobertura y el interés que cabría esperar ante el hecho incontestable de la separación política de América ${ }^{71}$. Asuntos más inmediatos $\mathrm{y}$ preocupantes polarizaban a las facciones en un clima de ingobernabilidad que facilitaría la intervención francesa en abril de 1823 y pondría fin a la segunda experiencia liberal. La pacificación de América se relegaría a un segundo plano y en su abordaje las posiciones se enconarían entre los partidarios de la solución militar y los que introducían la pertinencia del reconocimiento de la independencia.

América se perdía ante la ignorancia de muchos y la inoperancia e impotencia de los poderes centrales. Eran tiempos de crisis política, precariedad económica e inestabilidad social. Lejos quedaba la firmeza y confianza con que se promovieron la R.O. de 11 de abril y las Instrucciones de 15 de abril de 1820. Los dos decretos de 1822 revelaban una actitud a la defensiva ante el riesgo de que se fueran al traste las ya escasas posibilidades de «convencer»e integrar a los disidentes en un modelo de Nación que se desmoronaba.

69 Gil Novales, 1980: 50-55. Varela Suanzes, 1996.

70 DSC, 13 de febrero de 1822: 2312.

71 Es conocido el contrapunto entre Fernández Almagro (1944) que entendía que la independencia no caló en la sociedad peninsular y Gil Novales (1979) que defiende la tesis de qué sí estuvo presente en la conciencia de los españoles. 
El marco normativo. Las Cortes se pronuncian y el Gobierno ejecuta. La distancia del Consejo de Estado

En la segunda fase negociadora las Cortes y el Gobierno cobraban protagonismo mientras el Consejo de Estado se mantendría a una cierta distancia. En el tablero se dirimiría la definición de las competencias de los comisionados y la pertinencia de que pudieran firmar armisticios o tratados provisionales. Las posiciones bascularían desde que se limitaran a oír proposiciones (decreto de 13 de febrero) hasta la posibilidad de que suscribieran tratados provisionales de comercio (decreto de 28 de junio), llegando a considerarse, ya en Sevilla, el que pudieran negociar una independencia con los mínimos costes.

Los días previos al final de la legislatura extraordinaria que sesionaría de 22 de septiembre de 1821 a 14 de febrero de 1822 fueron de febril actividad. Continuarían las discrepancias sobre cómo enfrentar la cuestión americana sobre la base del fracaso generalizado de las negociaciones pasadas. El día 12 de febrero con presencia, a petición de las Cortes, de los secretarios de Guerra (José Cienfuegos) y de Gobernación de Ultramar (Ramón López Pelegrín), la Comisión de Ultramar presentaba un dictamen favorable al envío de comisionados para tratar la pacificación ${ }^{72}$. Oída la Comisión, los diputados procedieron al debate con las intervenciones destacadas del novohispano Lucas Alamán y del conde de Toreno. Alamán propuso que los comisionados tuvieran más facultades que las que el dictamen les confería; para Toreno el envío de comisionados podría entenderse como una acción de diplomacia, un reconocimiento tácito de la independencia, si no se explicitaba que la soberanía española estaba fuera de toda cuestión ${ }^{73}$. El Decreto de las Cortes extraordinarias de 13 de febrero sintetizaba en cinco puntos los términos de la negociación. Como en la etapa anterior, era el gobierno el que había de nombrar a los comisionados seleccionando a sujetos idóneos por su talento e instrucción. En lugar de presentarse a las autoridades españolas, como se estipuló en la R.O. de 11 abril 1820, los designados debían dirigirse a los diferentes gobiernos establecidos en las «Américas Españolas» para escuchar sus proposiciones y trasmitir-

72 La formaban el conde de Toreno (Asturias), Moscoso (Galicia), Espiga (Cataluña), Cuesta (Ávila), Álvarez Guerra (Extremadura), Oliver (Cataluña), Paul (Caracas) y Murfi y Gómez Navarrete (Nueva España). Varios de sus miembros presentaron votos particulares: Oliver denunciaba la escasa operatividad de la política americana y exigía responsabilidades al secretario de Ultramar; Moscoso y Toreno, en la línea moderada, proponían la salida de las Cortes de los diputados americanos de las provincias que habían proclamado la independencia; en una tercera banda los americanos Murfi, Gómez Navarrete y Paul solicitaban que se aprobara sin tener en cuenta los votos particulares.

73 DSC, 12 febrero de 1822: 2272-2298. 
las a la metrópoli, con excepción de aquellas que lesionaran la libertad de los españoles europeos y americanos para disponer de sus personas y bienes. En tanto se mantuviera la disensión convenía que el Gobierno hiciera una declaración destinada a los países con los que mantenía relaciones amistosas en el sentido de que la Nación española entendería como una violación a los tratados internacionales suscritos el reconocimiento parcial o absoluto de la independencia de las provincias de Ultramar. Para poder defender y conservar a las que se mantenían leales el Gobierno debía proponer a las Cortes la aprobación de los recursos necesarios. La preocupación por la situación de Nueva España, a la que se aludía expresamente para declarar la nulidad de los Tratados de Córdoba, no se correspondía con mención alguna sobre lo que estaba aconteciendo en el Perú 74 .

La promulgación del Decreto no puso fin a las divergencias acerca de la conveniencia de la política negociadora y los términos de su implantación y sería sometido a revisión por la Comisión de Ultramar ${ }^{75}$. En el dictamen que presentaba a las Cortes el 25 de junio para su discusión y aprobación hacía un seguimiento del resultado de las negociaciones emprendidas en 1820. En el caso de Venezuela y Nueva Granada coincidía con la tendencia dominante de responsabilizar de la guerra a la mala fe del jefe «de aquellos disidentes» que había mostrado «constante repugnancia a oír las proposiciones de paz y conciliación que les hicieron los comisionados por S.M. que llegaron en aquella época», y fue por esta actitud por la que el gobierno español no había recibido a los agentes plenipotenciarios enviados por Bolívar. En las provincias del Río de la Plata ni se había permitido que desembarcaran los comisionados porque no aceptaron hacer el reconocimiento previo de la independencia. En el Perú, «los que llegaron a Lima tampoco tuvieron mejor suerte en las repetidas veces que se abrieron negociaciones con el jefe del ejército titulado libertador, que invadió desde Chile las provincias del Perú, y se halla ahora dueño de la capital» $\gg^{76}$.

Al final la Comisión, tras hacer balance de lo ocurrido hasta entonces, proponía: $1 .^{\circ}$ Que se autorizara al Gobierno para que procediera como entendiera oportuno en cada situación; 2. ${ }^{\circ}$ Que se protegieran las vidas y propiedades de

74 Colección de los Decretos y órdenes generales expedidos por las Cortes extraordinarias que comprende desde 22 de setiembre de 1821 hasta 14 de febrero de 1822, impresa por orden de la misma, 1822, VIII: 272-274. Copia en AGI, Indiferente General 1570.

75 La integraban en junio de 1822, Gil de la Cuadra (Madrid), Valdés (Sevilla), Murphy (Canarias), Quiñónez (Puerto Rico), Cuevas (Valencia), Ibarra (Guatemala) y Ferrer (Guipúzcoa).

76 DSC, 25 de junio de 1822: 2157. 
los leales a la monarquía, tanto los que quisieran regresar a la Península como los que decidieran permanecer en aquellas provincias; $3 .^{\circ}$ Que no se interrumpieran en ningún caso las relaciones mercantiles mantenidas a través del comercio en puertos y con banderas neutrales; $4 .^{\circ}$ Que se hicieran todos los esfuerzos para evitar la extensión de la insurgencia a Cuba y Puerto Rico ${ }^{77}$. Terminada la exposición del dictamen, Ibarra, diputado por Guatemala, emitía un voto particular en contra y argumentaba su postura favorable al reconocimiento de la independencia en que así lo quería la mayoría de las provincias y en que la continuación de la guerra solo podría causar perjuicios a España y beneficios a los extranjeros, que la fomentaban en secreto. El envío de comisionados en las condiciones que especificaba la Comisión, es decir, solo con facultades para escuchar, no sería de ningún provecho ${ }^{78}$.

En el debate que siguió participaron algunos de los diputados más influyentes, significándose Antonio Alcalá Galiano y Francisco Javier Istúriz por los liberales exaltados, y Agustín Argüelles y Joaquín Ferrer por los moderados. Alcalá Galiano, contrario al dictamen, también se pronunció a favor del reconocimiento de la independencia. En su criterio los comisionados tendrían que actuar en un doble sentido: de un lado potenciando la unión con las provincias que desearan formar parte de la Monarquía y de otro lado respetando la decisión de aquellas que se habían "sacudido el yugo» porque a pesar de que, como en el caso de Buenos Aires, estuvieran sumidas en la guerra civil, en ningún caso se habían planteado unirse de nuevo a España. La única posibilidad para que la negociación obtuviera resultados estaba en plantear a los americanos que si querían la independencia se les concedería, pero mediante la firma de tratados ventajosos para todas las partes ${ }^{79}$. Argüelles lamentaba las circunstancias en las que se estaba debatiendo una cuestión de tanto calado, con prisas y sin margen para la reflexión (simultáneamente se estaba discutiendo la reforma del Código Penal). Entendía que las negociaciones debían ir acompañadas de una presencia militar que garantizara el cumplimiento de los acuerdos para que no se reprodujeran los comportamientos de Buenos Aires, Costa Firme y Nueva España. Recuperaba el espíritu de la R.O. de 11 de abril de 1820 al considerar del mayor interés que los comisionados recordaran a las provincias que el gobierno era firme y justo y que en medio de las desavenencias se podían encontrar puntos de acuerdo sobre la base de los principios liberales, sin hacer concesiones excesivas que serían interpretadas como un signo de debilidad por los gobiernos extranjeros. Con el envío de comisionados

77 DSC, Ibidem: 2159.

78 DSC, Ibidem: 2160.

79 DSC, Ibidem: 2162-2163. 
España probaba sus buenas intenciones, y si la guerra se mantenía era porque así lo querían los disidentes, por lo que se trataba de una guerra justa, de legítima defensa ${ }^{80}$.

Al día siguiente el duelo dialéctico volvía a ser protagonizado por Alcalá Galiano, Istúriz y Argüelles. El primero reiteraba que no estaba en contra del envío de fuerzas navales, pero que lo mejor que podía desear a su Nación era que los americanos se independizaran. Argüelles se situaba tan distante de restablecer el «duro cetro de hierro» como de conceder la emancipación absoluta, «tal vez si las desavenencias siguiesen y no se terminan por una negociación especial, están muy expuestas aquellas provincias a pesar de lo que se llama dominación española a dominación extranjera, bajo la cual no creo yo que puedan disfrutar mayores ventajas...». Entendía que los comisionados iban más autorizados y con mayores posibilidades que en la época anterior, por lo que no era improbable que se llegase a la reconciliación. En este punto, Istúriz, que se había pronunciado a favor de que los comisionados fueran investidos con capacidad de decisión, pedía la comparecencia del secretario de Despacho de Ultramar. Ante su ausencia era el de Estado, el moderado Francisco Martínez de la Rosa, el que tomaba la palabra en nombre del Gobierno. Evitando el compromiso, distinguía entre la opresión del absolutismo y los beneficios del constitucionalismo recordando las bondades de la «historia de nuestra dominación en América». Pedía a las Cortes que dieran al Gobierno las máximas competencias posibles para tratar una política tan compleja como la negociación, porque no todos los territorios americanos estaban en la misma posición ni albergaban las mismas expectativas ${ }^{81}$. Finalmente el 28 de junio de 1822 un nuevo decreto de las Cortes ratificaba, con modificaciones, el de 13 de febrero. Se reforzaban las competencias del Gobierno en lo relacionado con los «negocios de Ultramar» y se ampliaban las facultades de los comisionados, que quedaban autorizados para celebrar y firmar convenios provisionales de comercio para evitar que se interrumpieran los intercambios en el curso de las negociaciones. El grueso del decreto se dedicaba a la situación de los «adictos a la metrópoli», ya fueran españoles peninsulares o americanos, instruyéndose a los comisionados para que protegieran sus bienes y propiedades, tanto si optaban por retornar o por permanecer en aquellos países, y para que fueran respetados cualesquiera que hubiera sido su conducta y opinión política, exceptuando a los oficiales del ejército español que hubieran desertado y se hubieran pasado al servicio de los disidentes. Y de manera expresa se pedía a los comi-

80 DSC, Ibidem: 2164-2166.

81 DSC, 26 de junio de 1822: 2188. 
sionados que hicieran los esfuerzos necesarios para evitar que la disidencia se extendiera a las provincias leales, particularmente Cuba y Puerto Rico. Para financiar los gastos que pudieran derivarse se acudiría a los presupuestos de los ministerios de Guerra y Marina y, si fuera preciso, a una partida extraordinaria ${ }^{82}$.

Los dos decretos se desarrollaban en tres documentos: las Prevenciones reservadas a los Comisionados nombrados por el Rey para las provincias disidentes de Ultramar (formuladas por la Comisión de Ultramar el 15 de mayo), las Instrucciones para los Comisionados destinados a las Provincias de Ultramar en consecuencia de lo dispuesto por el Decreto de las Cortes extraordinarias de 13 de febrero de este año (de 15 de mayo firmadas por el ministro de Ultramar Diego Clemencín) y la Instrucción adicional aprobada por SM para los comisionados destinados a las Provincias de Ultramar (4 de agosto) ${ }^{83}$. En las Prevenciones y las Instrucciones se cruzaban el legislativo y el ejecutivo con la ratificación real. Las primeras aconsejaban mientras que las Instrucciones eran de obligado cumplimiento. El denominador común era practicar la prudencia y la precaución para tratar de evitar lo inevitable.

Las Prevenciones apercibían a los comisionados de que usaran sus habilidades para ganarse a aquellos que no se decidían ni a favor ni en contra de la unión con la «metrópoli», y aprovecharan el cansancio de la larga guerra provocada por «conspiradores extranjeros», para demostrarles las ventajas de acogerse a las propuestas de paz. Puesto que los indios y gente de color eran los que más respetaban al Rey, si en el curso de las negociaciones se planteaban temas vidriosos como la libertad de los esclavos y la ciudadanía ya concedidas en algunos de esos países, los comisionados debían emplear la prudencia y advertirles que la Constitución ya les otorgaba suficientes derechos y libertades. Tenían que evitar a toda costa —y esto estaba ya en la R.O. de 11 de abril de 1820 - , que potencias extranjeras se inmiscuyeran en lo que eran «disensiones de familia» y oponerse a cualquier atisbo de reconocimiento de las independencias y al nombramiento de agentes diplomáticos entre los disidentes y otros países. Debían actuar con la máxima cautela en el manejo de la información para evitar que la correspondencia con los jefes del ejército nacional y con las autoridades fuera interceptada. De nuevo, como era una constante des-

82 Decreto XCIV: «Se autoriza al Gobierno para que proceda respecto de los negocios de Ultramar según conviniere y lo exijan las circunstancias», Colección de los Decretos y Órdenes generales expedidos por las Cortes desde el primero de marzo hasta el 30 junio de 1822, 1822, IX: 499-450. AGI, Indiferente General 1570.

83 AGI, Ibidem. 
de los inicios de la política negociadora, si los disidentes mostraban su deseo de jurar la Constitución se les ofrecería el olvido de lo pasado ${ }^{84}$.

Las Instrucciones de 15 de mayo eran 36, frente a las 51 de las de 15 de abril de 1820. Mostraban puntos de coincidencia, como nombrar a dos comisionados por destino, la respuesta a dar si los disidentes introducían el reconocimiento de la independencia, y el presentar la guerra como un mal no deseado que se desarrollaría por medios civilizados. Pero divergían en que en las de 1822 las decisiones provenían de las Cortes, como representación de la Nación, y los comisionados estaban dotados de mayores facultades para tomar decisiones, que en cualquier caso deberían ser comunicadas al rey a través del ministerio de Ultramar que tomaría las resoluciones oportunas; y no se dirigirían a las autoridades españolas en Ultramar sino a los «gobiernos establecidos de aquellos países», a los que, sin reconocerlos como independientes se les daba una entidad que provocaría controversia. En las Instrucciones de 1820 no se prestaba atención al comportamiento de los comisionados, mientras que en las de 1822 se perfilaba hasta en aspectos muy concretos. Ahora, si el «gobierno establecido» se negaba a admitirles, los comisionados no se retirarían «sino después de haber agotado todos los medios de la razón y la prudencia» para que no se pudiera culpar al gobierno de S.M. de no haber intentado poner fin a la discordia. En el caso de ser aceptados exigirían ser reconocidos como representantes del Rey. En su primera nota ofrecerían en nombre de la «Nación española» la paz y la conciliación bajo el manto de la Constitución, puesto que lo que más les convenía a los disidentes era «establecer un pacto indisoluble de relaciones y confraternidad con la Península». Siguiendo lo estipulado en el Decreto de 13 de febrero se abstendrían de contradecir abiertamente a los disidentes, aun si estos intentaran desacreditar el sistema constitucional, valiéndose de la «persuasión y la dulzura» para suavizar aristas. Era su misión defender los derechos de los españoles europeos y americanos a trasladarse con sus familias y disponer de sus bienes, y la misma norma se aplicaría a los españoles peninsulares y americanos residentes en Europa. Si se trataba la cuestión de los indios, las castas y las gentes de color, se llamaría la atención sobre cómo la Constitución abría las puertas para su mejora. Si los disidentes introducían en las conversaciones el reconocimiento de la independencia los comisionados habrían de hacer gala de su talento para argumentar que la verdadera independencia era la que proporcionaba la Constitución, porque situaba a los integrantes de la Nación de uno y otro lado en situación de igualdad a través del sistema representativo. Si surgiese la pregunta sobre si las actuales comisiones

84 AGI, Ibidem. 
eran continuación de las de 1820, deberían responder tajantemente que no porque estas habían sido producto de un decreto de las Cortes y porque su objeto era distinto ya que «los gobiernos establecidos en América» tenían mayor capacidad para manifestar sus pretensiones. En esa línea se les debía estimular para que enviaran delegados a la Corte autorizados para «resolver» ${ }^{85}$.

A las Instrucciones se añadía el 4 de agosto la Instrucción adicional que consideraba los cambios del Decreto de 28 de junio incidiendo en dos cuestiones: la primera tenía que ver con la libertad que había de darse a los europeos americanos que desearan permanecer en «aquellos payses de Ultramar» y a los que optaran por regresar, que debía hacerse extensiva a los oficiales que se unieron a los disidentes y luego se arrepintieron; la segunda con las prerrogativas de los comisionados para firmar convenios provisionales de comercio, como una manera para que no se rompieran las relaciones mientras se lograba la conciliación. Conectando con el artículo 8 de las Instrucciones de 15 de mayo el rey consideraba conveniente que se reforzara la autoridad de los jefes militares, a los que debían reportarse los comisionados en el caso de que «algún gobierno disidente» creyera conveniente plantear el cese de hostilidades como condición preliminar para negociar y que debían encargarse de sentar las bases de un posible armisticio ${ }^{86}$.

El Consejo de Estado en esta segunda fase se mostró cauto. Cuando tuvo que dictaminar en relación con el decreto de 13 de febrero a partir del informe presentado por la Comisión de Ultramar, según el cual los comisionados no debían tener capacidad para entrar en el fondo de las negociaciones, optó por no pronunciarse, aduciendo falta de elementos de juicio ${ }^{87}$. Y cuando el 4 de mayo de 1822 se dirimían de nuevo las competencias de los comisionados de cara a la preparación de las Instrucciones y tenía que pronunciarse sobre la propuesta elaborada, esta vez por la Comisión de Gobernación de Ultramar nombrada por el Gobierno moderado, que entendía que los comisionados se debían atener al Decreto de 13 de febrero y actuar de acuerdo con los jefes superiores y demás autoridades legítimas, sin comprometer el honor de las armas, y recomendaba el envío de refuerzos militares, se ponía de manifiesto hasta que punto el Consejo era una institución no cohesionada ${ }^{88}$. La última in-

85 AGI, Ibidem.

86 Oficio a los jefes políticos, Madrid, 4 de agosto de 1822, AGI, Ibidem.

87 Acta del Consejo de Estado, 20 de marzo de 1822, AHN, Estado, Actas del Consejo de Estado, Libro 26.

${ }^{88}$ La opinión de los consejeros no fue unánime: Taboada entendía que los comisionados debían estar autorizados para reconocer la independencia bajo el supuesto de que se establecieran monarquías constitucionales con un príncipe de la casa de España al frente; Cevallos fue 
tervención se producía a comienzos de agosto, ya aprobadas las instrucciones de 15 de mayo y el decreto de 28 de junio, que el Consejo consideraba pertinentes ${ }^{89}$.

En cuanto a la posición del Gobierno en relación con la negociación replanteada, el secretario de Ultramar José María Moscoso de Altamira reconocía ante las Cortes en marzo de 1822 que la primera iniciativa se había truncado, no por falta de voluntad del rey sino porque los disidentes exigían el reconocimiento de su independencia. Venezuela seguía concitando la atención del Gobierno, una vez que después de diez años de guerra destructora el general español Morillo y el «caudillo disidente» habían firmado un armisticio y acordado que en caso de volver a las hostilidades se pelearía «como es costumbre en los países civilizados». Los comisionados enviados en 1820 habían ofrecido a Bolívar sendos buques para trasladar a la Península delegados que propusieran las medidas necesarias para restablecer la paz, y a los diputados elegidos a Cortes. Sin embargo se había abortado la iniciativa porque mientras el ejército nacional observaba el armisticio, los disidentes lo rompían y ocupaban la ciudad de Maracaibo, reanudándose la guerra con suerte favorable para los insurgentes que entraron en Caracas causando «inauditos desórdenes», lo que fue aprovechado por el «jefe disidente» para solicitar la firma de un nuevo armisticio con la condición de que le fueran entregados territorios estratégicos. La respuesta del general realista Miguel de la Torre, que había sucedido a Morillo, con acuerdo de la Junta de Pacificación, fue exigir el cumplimiento de las propuestas de los comisionados pacificadores. Más radical fue Bolívar en Nueva Granada donde cerró la posibilidad de toda medida de conciliación ${ }^{90}$. Sobre el envío (en 1820) de comisionados de pacificación a Chile no tenía información y en cuanto a Buenos Aires el ministro abundaba en lo ya advertido en la Proclama de 31 de marzo de 1820, en el sentido de que la separación les había llevado a la guerra civil. También allí el rey había enviado comisionados, pero sus gobernantes se negaron a entrar en negociaciones «sin el preliminar de reconocer su independencia» y tuvieron que regresar. Con respecto al Perú, con año y medio de retraso Moscoso analizaba las negociaciones de Miraflores:

partidario de que las misiones fueran acompañadas por fuerzas navales, Acta del Consejo de Estado, 4 de mayo de 1822, AHN, Estado, Actas del Consejo de Estado, Libro 26.

89 Acta del Consejo de Estado, 3 de agosto de 1822, AHN, Actas del Consejo de Estado, libro 26.

90 Memoria leída a las Cortes por el señor encargado de la Secretaría de Estado y del Despacho de la Gobernación del Reino para Ultramar, DSC, 6 de marzo de 1822: 201-211. Para la trayectoria de Moscoso de Altamira, Gil Novales, 2010: 2100-2101. 
El jefe político superior del Perú, en consecuencia de las órdenes de S.M., hizo una tregua de algunos días con el jefe «disidente» para tratar de pacificar y poner término a tanta calamidad. Tuvieron algunas conferencias en Mira-Flores por comisionados de una y otra parte, y se propuso por los del jefe político la negociación de un armisticio; pero el disidente, llevando adelante su propósito de insurreccionar todo el país, y hacer que de grado o por fuerza se proclamase la independencia, no solo desechó aquella propuesta, sino las demás que se le hicieron de jurar la Constitución, elegir diputados a Cortes y enviar comisionados a la Península contestando por toda razón que no podía contradecir los principios adoptados por los gobiernos libres de América. Se reunieron en este intermedio en Lima y su inmediación algunas tropas nacionales que vinieron de Arequipa, y otras del ejército del Alto Perú que bastaban para combatir a las de San Martín; pero faltaban buques con que resistir a los de Cochrane que tenían bloqueado el Callao, con lo cual dificultaba las subsistencias en Lima empeorando su situación ${ }^{91}$.

Que el conflicto armado se extendía por las provincias continentales lo prueba la contundencia de las intervenciones de Luis Balanzat y Dionisio Capaz, secretarios de Guerra y de Marina respectivamente, con el interés añadido de que el segundo había estado destinado en el Perú y había participado como comisionado de Pezuela en las negociaciones de Miraflores. Balanzat también se hacía eco de la inoperancia de la conciliación:

$\mathrm{Ni}$ el feliz cambio de nuestro sistema político ni las medidas conciliadoras que se emplearon, fueron bastantes para calmar la agitación, ni menos produjeron el resultado que se deseaba las negociaciones que principiaron a establecerse. La guerra, pues, continua sus estragos en algunos de aquellos lejanos países, mientras otros gozan del bien inestimable de la tranquilidad unidos a la madre Patria ${ }^{92}$.

En el recorrido obligado por las provincias comenzaba con Venezuela donde la suerte era claramente adversa a los «nacionales» una vez que Bolívar había roto cualquier posibilidad de un acuerdo y sus fuerzas habían avanzado logrando victorias decisivas como la de Carabobo el 24 de junio de 1821. El ejército español se encontraba desabastecido y aislado y otro tanto sucedía en Nueva Granada tras la pérdida de Cartagena. Sobre el Virreinato del Perú era más explícito que sus compañeros de gabinete porque para entonces tenía noticias de primera mano recibidas en octubre de 1821 a través de Valleumbroso y Seoane. Sabía de la deposición de Pezuela en Aznapuquio y de la evacuación de Lima por La Serna, pero obviaba referirse a Miraflores y Punchauca e insistía en que la paz no llegaría sino después de que se ganara la guerra para lo que era esencial el envío de refuerzos marítimos ${ }^{93}$.

91 Memoria, Moscoso, DSC, 6 de marzo de 1822: 204.

92 Exposición leída a las Cortes por el Secretario de Estado y del Despacho de la Guerra, DSC, 4 de marzo de 1822: 123. Para la trayectoria de Balanzat, Gil Novales, 2010: 315.

93 Exposición, Balanzat, DSC, 4 de marzo de 1822: 125. 
El secretario de Marina Dionisio Capaz presentó su Memoria a las Cortes en octubre de 1822, cuando la política española había dado un giro, una vez que desde el 5 de agosto los exaltados gobernaban el país. Su apuesta por la pacificación militar era elocuente, pero desafortunadamente por el lamentable estado de la Armada no se habían podido atender las demandas de auxilio del virrey del Perú ${ }^{94}$.

Las últimas Memorias del Trienio se presentaron ante las Cortes que iniciaban sesiones el 23 de abril de 1823 en Sevilla, adonde se habían trasladado debido a la intervención francesa. El gobierno había sido cesado por el rey el 18 de febrero, pero los ministros se mantendrían con carácter provisional hasta leer sus Memorias. Los días 4, 5 y 7 de mayo fue el turno del secretario de Ultramar José Manuel Vadillo que hizo una aproximación genérica dedicada a afirmar las bondades del sistema español y a descalificar a los disidentes ${ }^{95}$. Sería durante la Década Ominosa, en el exilio de Londres donde publicaría de manera anónima en 1829, Apuntes sobre los principales sucesos que han influido en el estado actual de la América del Sur. Allí explicaba las razones de las negociaciones que obedecían a la necesidad de adoptar medidas que pusieran fin al derramamiento de sangre y a la discordia entre los españoles de ambos mundos y por eso «con suma prudencia» se determinó que se nombrasen comisionados que pasaran a distintos puntos de América para informarse y oír proposiciones, sin hacer valoraciones ni balance ${ }^{96}$.

\section{El escenario americano}

De nuevo era el Gobierno el que seleccionaba a los comisionados que debían acometer tan complicada misión cuyos nombres y destinos daba a conocer el secretario en el Despacho de Ultramar Diego Clemencín a lo largo del mes de mayo de 1822. La financiación de la operación recaería en las Cajas de La Habana en el caso de los diputados a Nueva España y Costa Firme, y en la Tesorería General en el caso de Chile, Perú y Buenos Aires ${ }^{97}$. A Nueva España

94 Memoria leída a las Cortes extraordinarias por el Secretario de Estado y del Despacho de Marina en sesión de 11 de octubre, DSC, 11 de octubre de 1822: 124-125. Publicada en Madrid, Imprenta Tomás Albán y Compañía, 1822. Para la trayectoria de Capaz, Gil Novales, 2010: 593-594.

95 DSC, Gaceta Española, 4 de mayo de 1823: 56; 8 de mayo de 1823: 73. Para la trayectoria de Vadillo, Gil Novales, 2010: 3076-3078.

96 Vadillo, 2006 [1829]: 420-421.

97 Previamente el ministro había circulado una petición a personajes relevantes para que propusieran nombres de sus candidatos, entre ellos estaba el ex ministro Porcel. 
irían Juan Jabat (reemplazado después por Juan Ramón Osés, miembro honorario del Superior Tribunal de Justicia) y Santiago Irisarri, brigadier de la Armada nacional; a Guatemala, Francisco del Pino, brigadier de los ejércitos nacionales; a Costa Firme, José Sartorio, brigadier de la Armada nacional, y Juan Barry capitán de fragata; al Río de la Plata, después de cambios en los nominados, el teniente coronel Luis de la Robla y Antonio Luis Pereyra, oidor de la Audiencia de Charcas ${ }^{98}$. Los comisionados a Nueva España partieron el 7 de octubre de 1822 y arribaron en enero de 1823 al castillo de San Juan de Ulúa, donde los españoles resistían desde octubre de 1821. Allí fueron informados de la situación por el comandante español general brigadier Francisco Lemaur e iniciaron las negociaciones con los agentes del emperador Iturbide, el coronel Francisco de Paula Álvarez, el capitán Eugenio Cortés y Pablo M. de la Llave (que había sido diputado en las Cortes) que llevaban instrucciones de no avanzar en ningún acuerdo sino se reconocía la independencia. Tras la destitución de Iturbide en abril de 1823, fue el gobierno republicano de Guadalupe Victoria el que mantuvo la posición de fuerza. Finalmente los comisionados se retirarían tras el ataque de Lemaur sobre Veracruz ${ }^{99}$. En cuanto a Guatemala, no se concretó la misión porque la región fue anexionada por México. Dos de los agentes que habían sido comisionados en 1820 para negociar en Venezuela y Nueva Granada, Sartorio y Barry, fueron instruidos para dar este nuevo impulso, sin embargo debido a la falta de financiación y la situación de insurgencia de la Costa Firme nunca llegaron a su destino ${ }^{100}$.

Los comisionados al Río de la Plata, La Robla y Pereyra, se reunieron en Río de Janeiro en febrero de 1823 y de ahí pasaron a Montevideo donde se comunicaron con Bernardino Rivadavia, entonces ministro de Gobierno y Relaciones Exteriores de la Provincia de Buenos Aires, que autorizó el traslado a la capital. Siguiendo las Instrucciones de 15 de mayo de 1822 gestionaron su reconocimiento como comisionados regios y el 4 de julio de 1823 se llegaba a la Convención Preliminar en el que se establecía la firma de un armisticio de 18

98 A finales de mayo Clemencín lo comunicaba a las autoridades, Minuta de R.O. circular a los Jefes de Ultramar acompañando nota de los comisionados nombrados para la Nueva España, Guatemala, Costa Firme y Buenos Ayres, y comunicándoles algunos puntos de las Instrucciones que se les han dado, Aranjuez, 31 de mayo de 1822, AGI, Indiferente General 1570.

99 Robertson, 1926: 42. Delgado, 1950, I: 193-240. Anna, 1986: 318. Sánchez Andrés, 2003: 32 .

100 Comunicación del Gobierno acerca de las negociaciones entabladas con los comisionados de Bolivar, 1822, ACD, Ultramar 22, núm. 20. Correspondencia de los comisionados para la pacificación de Venezuela, José Sartorio y Juan Barry, 1820-1823, AGI, Indiferente General 1571. Robertson, 1926: 43. Anna, 1986: 319. 
meses sin que se cortaran las negociaciones, según el cual las fuerzas españolas en el Perú conservarían sus posiciones y se restablecerían las relaciones comerciales entre las provincias de la monarquía española, las que ocupaban en el Perú las armas nacionales y los estados que ratificasen la Convención ${ }^{101}$. En el tiempo del armisticio el gobierno de Buenos Aires, con autorización de la Junta de Representantes, negociaría un tratado definitivo de paz y amistad entre España y los estados del continente americano. Era un paso importante pero después vendría el arduo camino de conseguir la adhesión de las provincias de lo que se encargó al general Juan Gregorio Las Heras, que también debía acercarse al virrey La Serna. Mientras Pereyra y La Robla esperaban el resultado de la misión de Las Heras tuvieron noticia de la vuelta al absolutismo y sus consecuencias. Sin que se ratificara la Convención decidieron cesar en su misión y retirarse a Montevideo ${ }^{102}$.

Pereyra y La Robla se interesaron por la situación del Perú. En su criterio la firma de la Convención Preliminar no perjudicaría al gobierno de La Serna y para hacérselo saber se comunicaron con él a finales de julio. Desde la sede del Cuzco, La Serna hacía valer su autoridad como jefe político superior, y enterado de la misión de Las Heras, para entrar en el circuito negociador designó al brigadier Baldomero Espartero, no sin mostrar su descontento porque desde la Corte no se le había informado oficialmente de la comisión de La Robla y Pereyra a Buenos Aires. El 7 de diciembre de 1823 Espartero llegaba a Salta para dar a conocer a Las Heras las proposiciones del gobierno del Perú en relación con lo planteado en la Convención Preliminar, siempre supeditadas a recibir las instrucciones del gobierno español. El escenario se había complicado una vez que el hombre fuerte del Alto Perú, Pedro Antonio de Olañeta había tomado cartas en el asunto y considerado que un arreglo entre Las Heras y Espartero suponía una imposición inaceptable ${ }^{103}$. El 20 de marzo de 1824 terminaba la comisión de Espartero sin resultado alguno ${ }^{104}$.

En cuanto a la proyección en el Perú, según la versión oficial en su momento no se habían nombrado comisionados porque no se había encontrado a personas idóneas. En realidad el Gobierno estaba supeditando la negociación al envío de recursos navales. El 14 de noviembre de 1822 el secretario de Des-

101 Convención Preliminar, Buenos Aires, 4 de julio de 1823, AGI, Indiferente General 1570.

102 Parte de la correspondencia de Pereyra y de La Robla con el secretario de Ultramar está en AGI, Indiferente General 1571. Robertson, 1926: 44. Caillet-Bois, 1939: 181-219.

103 Correspondencia de La Serna con el Brigadier de los Reales Ejércitos D. Baldomero Espartero, Cuzco, 28 de marzo de 1824, Torata, 1894, I: 145-146.

104 Roca, 2007: 501-539. Laserna, 2010: 363-367. 
pacho de Guerra, Navarro Aliguer, se dirigía a La Serna anunciándole que por decreto de 13 de febrero las Cortes habían resuelto enviar comisionados a los gobiernos establecidos en las provincias disidentes de Ultramar para oír y recibir sus proposiciones y trasmitirlas a la metrópoli, y que por otro de 28 de junio habían dispuesto que dichos comisionados fueran autorizados para celebrar tratados provisionales de comercio con los que pudieran continuarse las negociaciones mercantiles entre aquellas provincias y la Península. Se había designado a los destinados a Nueva España, Guatemala, Buenos Aires y Costa Firme y restaba nombrar a los del Perú, «lo que se verificará tan luego las fuerzas marítimas destinadas a esos mares vayan a dar la vela». Siempre, en el caso de que se llegara a armisticios, los comisionados debían obrar de acuerdo con los jefes militares ${ }^{105}$. Meses más tarde, en febrero de 1823, el secretario de Guerra comunicaba que había sido designado el capitán del batallón de Burgos Ramón Martínez de Campos y pasaba a La Serna un oficio para que se le abonaran los haberes correspondiente a los gastos de viaje ${ }^{106}$. Las gestiones se dilataron y la misión de Martínez de Campos derivaría por un camino diferente al señalado en las Instrucciones de 15 de mayo de 1822.

\section{BALANCE}

El último debate sobre las negociaciones se produjo a comienzos de agosto de 1823 cuando las Cortes ya sesionaban en Cádiz acorraladas por la progresión de las tropas francesas. La Comisión de Ultramar ${ }^{107}$, después de la lectura de la Memoria del ministro Vadillo, presentaba a la aprobación de la Cámara un dictamen de tres puntos en el que proponía que se invitara a «los gobiernos de hecho de las provincias disidentes» a enviar comisionados con plenos poderes a un punto neutral de Europa a encontrarse con los plenipotenciarios nombrados por S.M. para que «estipulen toda clase de tratados sobre las bases que se consideren más a propósito, sin excluir las de independencia en caso necesario», aunque nada tendría valor hasta que no lo aprobaran las Cortes ${ }^{108}$. Por el Gobierno el secretario de Hacienda (Juan Antonio Yandiola) daba razones

105 Orden dirigida por el secretario del Despacho de Guerra al jefe politico superior del Perú D. José de la Serna, Madrid, 14 de noviembre de 1822, AGI, Indiferente General 313.

106 Oficio del secretario de Guerra (era Miguel López Baños), Palacio, 23 de febrero de 1823, AGI, Ibidem.

107 La componían los diputados Álava, Sánchez, Varela, Meléndez, Quiñónez, Alcántara, Bringas y Murphy, DSC, Madrid, 2 de marzo de 1823: 7.

108 DSC, Gaceta Española, Cádiz, 3 de agosto de 1823: 402. 
sobre la inconveniencia del dictamen. El escenario internacional no permitía fijar un lugar neutral, y sobre todo, las disensiones con América eran «diferencias de familia» y si se aprobaba la propuesta se les daría otro carácter y además se modificaría el decreto de las Cortes sobre el nombramiento y facultades de los comisionados. Se cruzaron entonces intervenciones a favor y en contra con Argüelles y Alcalá Galiano de nuevo en la avanzada. Argüelles se oponía, en primer lugar porque el Gobierno, según había manifestado, ignoraba el resultado de las misiones de los comisionados. La aprobación del dictamen suponía un obstáculo para el desarrollo de su encomienda y además, cualquiera que fuera el desenlace de las negociaciones, no había garantía de que los gobiernos americanos cumplieran lo pactado. Alcalá Galiano reiteraba que era imposible reducir a la obediencia a las provincias de Ultramar, y discrepaba con la afirmación de Argüelles de que era indecoroso que fuera la nación española la que propusiera la independencia. Creía que toda negociación era inútil mientras España mantuviera su actitud de potencia dominadora y que la única salida era admitir la separación política y hacerlo en condiciones ventajosas. La discusión se prolongaría en sesión extraordinaria del 3 de agosto y finalmente se decidía no votar el dictamen ${ }^{109}$.

Ya no quedaba margen. El primero de octubre las tropas francesas liberaban a Fernando VII confinado en Cádiz. El mismo día firmaba un decreto anunciando la derogación de la Constitución y la anulación de todas las medidas que se habían tomado desde el 7 de marzo de $1820^{110}$. La cascada de retroacciones culminó con el Decreto de 26 de enero de 1824 que revocaba el nombramiento y las competencias de todos los comisionados, ordenaba su retorno, y prohibía cualquier tipo de negociación:

Enterado de las negociaciones que han entablado en diferentes puntos de América varios individuos que se dicen comisionados nombrados por el gobierno constitucional para tratar con los disidentes de aquellas provincias sobre su pacificación, y en cuyas negociaciones se ha intentado establecer por base preliminar la de que el Gobierno de España no está distante de reconocer la independencia de aquellos países; he venido en declarar nulos y de ningún valor ni efecto los poderes de todos y cada uno de los expresados comisionados y enviados a América por el gobierno llamado constitucional; y por consiguiente cuantos actos hayan ejecutado y ejecuten en virtud de ellos, que sean contrarios a los legítimos derechos de la Corona de España y a mi Real soberanía, felizmente restablecidos; mandando que dichos Comisionados cesen y se retiren inmediatamente a la Península. En su consecuencia, y

109 DSC, Gaceta Española, Cádiz, 4 de agosto de 1823: 407-409.

110 Decretos y Resoluciones de la Junta Provisional, Regencia del Reino, y los expedidos por su Majestad desde que fue libre del tiránico poder revolucionario, Madrid, Imprenta Real, 1824, VII: 147. 
a fin de que la referida mi Real resolución tenga el debido cumplimiento, mando a mis virreyes, capitanes generales y gobernadores intendentes de ambas Américas y sus Islas adyacentes, la hagan publicar en los territorios de sus respectivos mandos, dando al tiempo las órdenes y providencias oportunas para que sin dilación se lleve a puro y debido efecto en todas sus partes ${ }^{111}$.

Era voz que clamaba en el desierto. Para entonces — a excepción de las Antillas - solo en algunas provincias del Perú se mantenía el sistema español. La preocupación por la situación de América recorrió la política americana del Trienio con dedicación desigual. Problemas más cercanos y perentorios ocuparon la agenda de los poderes centrales en la etapa breve y convulsa del segundo liberalismo, en la que el conflicto a distintas bandas fue seña de identidad. Liberales contra absolutistas recalcitrantes, liberales moderados frente a exaltados radicales, modernización frente a fórmulas del Antiguo Régimen profundamente arraigadas. Y, mientras, en las provincias continentales de Ultramar la insurgencia avanzaba. La política de pacificación estuvo condicionada por la limitada información sobre lo que sucedía en América debido a la distancia y a las dificultades crecientes para la circulación de correspondencia entre las autoridades españolas peninsulares y americanas. Las noticias llegaban con retraso y las disposiciones que se generaban en la Corte se aplicaban cuando la realidad que las había motivado ya había cambiado, en una suerte de desencuentros concatenados. Así sucedió con la negociación que fue la apuesta del segundo liberalismo para restaurar la integridad de la Monarquía.

Comparativamente la historiografía especializada se ha ocupado en menor medida del Trienio Liberal que del liberalismo de las Cortes de Cádiz. La negociación surca investigaciones globales y ha sido objeto de atención de investigaciones sobre casos regionales. En el artículo se entiende la política de la negociación y su aplicación en América como un proceso con distintas caras. Para interpretarlo se han desentrañado las coordenadas generales en las que se gestó y desarrolló, las instancias que se implicaron, el marco normativo, los debates que se generaron, y cuál fue su proyección en los distintos escenarios americanos.

La dinámica de la política central y el contrapunto de los sucesos ultramarinos han permitido diferenciar dos etapas. En la primera, intervinieron el Rey, la Junta Provisional, el Gobierno y el Consejo de Estado, y las Cortes se sumaron desde la apertura de sesiones el 9 de julio de 1820. Desde la confianza en las posibilidades de salvar la integridad de la Nación española, las negociacio-

111 AGI, Indiferente General 1571. 
nes se conciben de arriba abajo, desde la seguridad de que la razón y la fuerza acompañaban. Se ofrecía a los disidentes el perdón y hacerles partícipes de las ventajas que les aportaba la Constitución de 1812, que debían acatar como condición imprescindible para entablar conversaciones. Si no aceptaban les esperaba la guerra y un futuro de enfrentamientos civiles que aprovecharían potencias extranjeras. El resultado negativo se fue conociendo y admitiendo desde finales de 1820, y a lo largo de 1821, el Gobierno, el Consejo de Estado y algunos diputados en las Cortes consideraron otras posibilidades, especialmente la solución militar y el reconocimiento de la independencia.

La Consulta del Consejo de Estado de 7 de noviembre de 1821 que postulaba la pacificación armada en el marco de la Constitución supondría el punto de inflexión hacia el relanzamiento de la negociación. La segunda etapa se encuadraba en los decretos de las Cortes de 13 de febrero y 28 de junio de 1822. El mapa peninsular y americano había cambiado, en un contexto en que los problemas arreciaban: el enfrentamiento entre facciones y las movilizaciones sociales erosionaban las bases y el funcionamiento del sistema liberal sumido en una profunda crisis económica. En el segundo envite negociador la superioridad y confianza pasadas dieron paso a una actitud de «prudencia», a la defensiva, que encubría la debilidad ante la realidad incontestable de la separación de las provincias. Sin reconocer la independencia, se admitía que se negociaba con «gobiernos establecidos». Los comisionados ganaban en competencias hasta tener la facultad, que les daba el decreto de 28 de junio, para sellar tratados provisionales de comercio, y apartando la intransigencia, se les encomendaba evitar por todos los medios que las negociaciones se rompieran.

El rey fue siempre contrario a cualquier resquicio que abriera la posibilidad del reconocimiento de la independencia. Si en el sexenio absolutista apostó sin ambages por la pacificación militar, en el Trienio, bajo presión de la Junta Provisional, los militares y la opinión pública — organizada en sociedades y logias y expresada en una intensa propaganda-, se plegó inicialmente a la vía de la negociación. Pero siempre confió en recuperar sus prerrogativas y buscó el apoyo de sectores leales y de las potencias absolutistas. La Junta Provisional, de carácter conservador, fue un elemento fundamental en la definición de la política negociadora moderando las veleidades autoritarias del Monarca.

Los secretarios más implicados, los de Ultramar, Guerra y de Marina bascularon desde la conciliación a considerar que fuera simultaneada con el acompañamiento de recursos militares. En 1822 reconocían ante las Cortes el fracaso de la negociación, y los de Guerra y Marina demandaban recursos para 
enviar refuerzos navales, aunque al tiempo reconocían su inviabilidad por la falta de medios económicos para levantarlos.

El Consejo de Estado tuvo un papel central a lo largo de todo el proceso. Fue requerido para elaborar dictámenes que fueron tenidos en cuenta por el ejecutivo y el legislativo en la toma de decisiones. Su posición ganó en dureza desde los dictámenes de marzo de 1820 a la Consulta de 7 de noviembre de 1821, que aconsejaba acudir al envío de recursos navales y a la mediación de potencias extranjeras, siempre en el respeto de la Constitución. A lo largo de 1822 se mostró progresivamente cauto y distante. Si bien los consejeros eran hombres de la confianza del Rey, el Consejo no se comportó como un bloque uniforme, los votos particulares desvelaban divergencias que cubrían un amplio abanico de posiciones que iban desde la conciliación hasta el reconocimiento de la independencia.

Las Cortes, en plenos, o a través de las comisiones, especialmente la de Ultramar, fueron un indicador fundamental para seguir las contingencias de la política negociadora en un marco en el que la dedicación a la tarea de cómo gobernar los territorios americanos fue dando paso a la preocupación por cómo mantenerlos. La salida de los diputados americanos continentales se hizo notar. El debate que llevó a los decretos de 13 de febrero y 28 de junio de 1822 , se abrió a propuestas que planteaban el reconocimiento de la independencia y la mediación de potencias amigas.

Pasando al escenario americano, Nueva España, Costa Firme, y hasta las ya independientes provincias del Río de la Plata, recabaron la atención de las instancias centrales, muy por delante del caso del Virreinato del Perú, relegado a un segundo plano a pesar de su peso relativo y de quedar como el último centro de poder de España en América. Su caso es un ejemplo paradigmático de los desajustes del Trienio en relación con la cuestión americana. Los cinco diputados suplentes por Lima, los únicos que se sentaron en las Cortes en representación de las provincias, no intervinieron en las sesiones para tratar asuntos relacionados con la pacificación. Los ministros en sus Memorias hacían referencia a la precaria información de que disponían y a su carácter extraoficial, y en sus comparecencias daban cuenta de situaciones que hacía meses que habían cambiado. La política negociadora encontró trabas añadidas especialmente en lo que concernía al Virreinato del Perú. En la primera etapa los dos comisionados designados rechazaron la encomienda y fue el virrey Pezuela el encargado de negociar con San Martín en Miraflores y de dar las instrucciones para que desde el Alto Perú se emprendieran conversaciones con los disidentes de las provincias del norte del Río de la Plata. La Serna recibió al comisionado que iba destinado a Chile con el que mantuvo una relación conflictiva que no modificó el resultado de las negociaciones con San Martín, 
irreductible en exigir el reconocimiento previo de la independencia. En la segunda fase no se nombraron comisionados al Perú aduciendo la poco convincente razón de que no se había encontrado a las personas idóneas. En el trasfondo estaba la voluntad compartida por las instancias centrales, virreyes y altos oficiales del ejército del Perú de que el mantenimiento del Virreinato pasaba por una solución militar.

Conciliación o guerra, ese fue el dilema. Ninguna de las dos posibilidades estaba en manos de los poderes peninsulares ni de las autoridades españolas. Progresivamente fueron los disidentes los que marcaron la pauta. La capitulación sentenciaría, desde Nueva España al Perú, pasando por la Costa Firme, la suerte final del dominio español en la América continental.

\section{FUENTES IMPRESAS Y BIBLIOGRAFÍA}

Anna, Timothy, España y la Independencia de América, México, FCE, 1986.

Artola, Miguel, La España de Fernando VII, Madrid, Espasa, 2008.

Broseta Perales, Salvador, «Las Cortes ante el proceso emancipatorio novohispano», Salvador Broseta, Carmen Corona, Manuel Chust et al. (eds.), Las ciudades y la guerra, 1750-1898, Castelló, Universitat Jaume I, 2002: 79-93.

Broseta Perales, Salvador, «Realismo, autonomismo e insurgencia: el dilema americano en las Cortes del Trienio Liberal», Trienio. Ilustración y Liberalismo, 41 (Madrid, 2003): 85-111.

Buldain Jaca, Blanca E., «La Junta Provisional de 1820: instalación y atribuciones», Revista de Historia Contemporánea, 1 (Sevilla, 1982): 39-64.

Buldain Jaca, Blanca E., «Las dinámicas de poder en la transición política de 1820», Revista de Derecho Politico, 30 (Madrid, 1989): 133-158.

Caillet-Bois, Ricardo, «La misión Pereyra-La Robla al Río de la Plata y la Convención Preliminar de Paz de 4 de julio de 1823», Boletín de la Academia Nacional de la Historia, XII (Buenos Aires, 1939): 175-223.

Colección Documental de la Independencia del Perú (CDIP), VI, Asuntos Militares, 3, Juntas de Guerra (1820-1821) (Felipe de la Barra, comp.), Lima, Comisión Nacional del Sesquincentenario de la Independencia del Perú, 1971.

Colección Documental de la Independencia del Perú (CDIP), XII, Documentación Oficial Española, 2 (Guillermo Lohmann Villena, comp.), Lima, Comisión Nacional del Sesquincentenario de la Independencia del Perú, 1972.

Colección Documental de la Independencia del Perú (CDIP), XIII, Obra Gubernativa y Epistolario de San Martín (José Agustín de la Puente Candamo, comp.), 
Lima, Comisión Nacional del Sesquincentenario de la Independencia del Perú, 1976.

Colección de Decretos y órdenes generales de la primera legislatura de las Cortes ordinarias de 1820 y 1821, desde el 6 de julio hasta el 9 de noviembre de 1820, VI, Madrid, Imprenta Nacional, 1821.

Colección de los decretos y órdenes generales expedidos por las Cortes extraordinarias que comprende desde el 22 de septiembre de 1821 hasta el 14 de febrero de 1822, impresa de orden de la misma, VIII, Madrid, Imprenta Nacional, 1822.

Colección de los decretos y órdenes generales expedidos por las Cortes desde el primero de marzo hasta el 30 de junio de 1822, IX, Madrid, Imprenta Nacional, 1822.

Colección de decretos y órdenes generales expedidos por las Cortes, Madrid, Imprenta Nacional, 10 vols., 1820-1823.

Costeloe, Michael, La respuesta a la independencia: la España imperial y las revoluciones hispanoamericanas, 1810-1840, México, FCE, 1989.

Cuesta Domingo, Mariano, «El Consejo de Estado ante la Independencia hispanoamericana», Revista de la Universidad Complutense, XXVI/107 (Madrid, 1977): 245-264.

Delgado, Jaime, España y México en el siglo XIX, I, Madrid, CSIC, 1950-1953.

Diarios de Sesiones de Cortes Generales, 1820-1823, Publicaciones de las Cortes Generales, Madrid, 5 CD-ROM, 2000. Consultado en la red en Fundación Centro de Estudios Constitucionales 1812, Cádiz www.constitucion1812.org.

Documentos del Archivo de San Martín, V, Buenos Aires, Imprenta Coni, 1910-1911.

Documentos del Reinado de Fernando VII. VII. El Consejo de Estado (1792-1834). Pamplona, Ediciones Universidad de Navarra, 1971.

Fehrenbach, Charles W., «Moderados and exaltados: the Liberal Opposition to Fernando VII, 1814-1832», HAHR, L/1 (1970): 52-69.

Fernández, Delfina, «Bolívar y La Torre: frustración de la esperanza de llegar a acuerdos de paz en Venezuela en el Trienio Liberal», Anuario de Estudios Bolivarianos, 3 (Caracas, 1994): 9-60.

Fernández Almagro, Melchor, La emancipación de América y su reflejo en la conciencia española, Madrid, Instituto de Estudios Políticos, 1944.

Fisher, John, «The Royalist Regime in the Viceroyalty of Peru 1820-1824», Journal of Latin American Studies, 32 (Cambridge, 2000): 55-84.

Fisher, John, Una historia de la Independencia del Perú. Diario político del comisionado de paz Manuel de Abreu (Introducción y selección documental de John Fisher), Madrid, Fundación MAPFRE-Doce Calles, 2009. 
Frasquet, Ivana, «La cuestión nacional americana en las Cortes del Trienio Liberal, 1820-1821», Jaime Rodríguez (coord.), Revolución, independencia y las nuevas naciones de América, Madrid, Mapfre, 2005: 123-158.

Frasquet, Ivana, Las caras del águila: del liberalismo gaditano a la República federal mexicana, 1820-1824, Castelló de la Plana, Universitat Jaume I, 2008a.

Frasquet, Ivana, «La senda revolucionaria del liberalismo doceañista en España y México, 1820-1824», Revista de Indias, LXVIII/242 (Madrid, 2008b): 153-180.

Gil Novales, Alberto, «La independencia de América en la conciencia española, 1820-1823», Revista de Indias, 157-158 (Madrid, 1979): 235-265.

Gil Novales, Alberto, El Trienio Liberal, Madrid, Siglo XXI, 1980.

Gil Novales, Alberto, «Paz en la guerra (en torno a la conciliación entre España y América», Trienio. Ilustración y Liberalismo, 33 (Madrid, 1999): 53-64.

Gil Novales, Alberto, Diccionario Biográfico de España (1808-1833). Desde los orígenes del liberalismo a la reacción absolutista, Madrid, Fundación MAPFRE, 2010 .

Gómez Rivero, Ricardo, La sanción real en la Constitución de 1812, Cádiz, Universidad de Cádiz, 2010.

Hamnett, Brian, La politica española en una época revolucionaria, 1790-1820, México, F.C.E., 1985.

Haro, Dionisio de, La reforma monetaria del Trienio constitucional: de la política monetaria ilustrada al reformismo liberal, Madrid, Dykinson, 2006.

Jensen, Silvina, «El problema americano en el Trienio Liberal. Análisis de las políticas de Ultramar en las Cortes españolas (1820-1823)», Trienio. Ilustración y Liberalismo, 28 (Madrid, noviembre, 1996): 51-98.

Laserna, marqués de la, José de La Serna, último virrey español, León, Akrón, 2010.

Lombardi, Ángel Rafael, «La nueva política liberal y sus consecuencias en el conflicto de la Costa Firme (1820-1823)», Ligia Berbesí y Belín Vázquez (comp.), Vínculos y sociabilidades en España e Iberoamérica siglos XVI-XX, Universidad del Zulia, Maracaibo, 2010: 194-212.

Martínez Riaza, Ascensión, «Las diputaciones provinciales en el sistema liberal español», Revista de Indias, LII/195-196 (Madrid, CSIC, 1992): 647-691.

Martínez Riaza, Ascensión, «Gobernar, pacificar, negociar. La política española en el Perú, 1820-1824», Tomás Straka, Agustín Sánchez-Andrés, Michael Zeuske (comps.), Las independencias de Iberoamérica, Caracas, Fundación Empresas Polar, UCAB, Fundación Konrad Adenauer, UMSNH.

Medina Plana, Raquel, «El Diario de Sesiones en el Trienio Liberal», Cuadernos de Historia del Derecho, 9 (Madrid, 2002): 29-120. 
Meza, Robinson, «Las políticas del Trienio Liberal y la independencia de Venezuela (1820-1823)», Anuario de Estudios Bolivarianos, XII/14 (Caracas, 2007): 81-96.

Nater, Laura, «En busca del reconocimiento: la independencia de América Latina y la política española, 1820-1823», Historia Mexicana, XLV/4 (México, abril-junio, 1996): 705-735.

Peralta, Víctor, La independencia y la cultura política peruana, Lima, IEP-Fundación Bustamante de la Fuente, 2010.

Pezuela, Joaquín, Memoria de Gobierno 1816-1821 (Vicente Rodríguez Casado y Guillermo Lohmann Villena, eds.), Sevilla, Escuela de Estudios Hispanoamericanos, 1947.

Pons Muzzo, Gustavo, Las conferencias de Miraflores y Punchauca y su influencia en la conducción de la guerra de la independencia en el Perú, Lima, Instituto Sanmartiniano del Perú, 1999.

Porras Barrenechea, Raúl, «La entrevista de Punchauca y el republicanismo de San Martín», Mar del Sur, II/12 (Lima, 1950): 22-33 / reeditada en Academia Nacional de la Historia de Buenos Aires, San Martín. Homenaje de la Academia Nacional de la Historia en el Centenario de su muerte (Buenos Aires, 1951): 171-184.

Puente Candamo, José Agustín de la, «La misión del marqués de Valle Umbroso y de Antonio Seoane: notas para su estudio», Revista Histórica, XXI (Lima, 1954): 426-457.

Puente Candamo, José Agustín de la, «El encuentro de Punchauca y la Independencia del Perú», José Antonio Benito (ed.), Pasado, presente y futuro de Lima Norte: construyendo una identidad, Lima, Fondo Editorial Universidades Sapientiae, 2007: 59-67.

Quintero Saravia, Gonzalo, Pablo Morillo, general de dos mundos, Bogotá, Planeta, 2005.

Robertson, William S., "The Policy of Spain towards its revolted colonies, 18201823», HAHR, 6 (1926): 21-46.

Roca, José Luis, Ni con Lima ni con Buenos Aires. La formación de un Estado nacional en Charcas, Lima, IFEA-Plural, 2007.

Rodríguez, Jaime (coord.), Revolución, independencia y las nuevas naciones de América, Madrid, Mapfre, 2005.

Rodríguez, Mario, «The American Question at the Cortes of Madrid», The Americas, 38/3 (Washington, 1982): 293-314.

Sánchez Andrés, Agustín, «La búsqueda de un nuevo modelo de relaciones en los territorios ultramarinos durante el Trienio Liberal (1820-1823)», Revista de Indias, 57/210 (Madrid, 1997): 451-474. 
Sánchez Andrés, Agustín, «De la independencia al reconocimiento. Las relaciones hispano-mexicanas entre 1820 y 1836», Agustín Sánchez Andrés y Raúl Figueroa Esquer (coords.), México y España en el siglo XIX. Diplomacia, relaciones triangulares e imaginarios nacionales, México, Universidad Michoacana San Nicolás de Hidalgo, 2003.

Sánchez Andrés, Agustín, «La administración central española y el gobierno de Ultramar en las postrimerías del Antiguo Régimen y las primeras décadas del régimen liberal, 1812-1863», Relaciones, XXVIII/112 (México, 2007): 185-215.

Sánchez Mantero, Rafael, Los Cien Mil Hijos de San Luis y las relaciones francoespañolas, Sevilla, Universidad de Sevilla, 1981.

Torata, conde de (Fernando Valdés y Héctor), Documentos para la historia de la guerra separatista del Perú, Madrid, Imprenta de la Viuda de M. Minuesa de los Ríos, 1894-1898, 5 vols.

Torres Lanzas, Pedro, Independencia de América, fuentes para su estudio, Sevilla, Imprenta Zarzuela, 1912, 6 vols.

Urquijo Goitia, José Ramón, Gobiernos y ministros españoles en la Edad contemporánea, Madrid, Consejo Superior de Investigaciones Científicas, 2008.

Vadillo, José Manuel, Apuntes sobre los principales sucesos que han influido en el estado actual de la América del Sur [1829] (edición de Alberto Gil Novales), Madrid, Fundación Mapfre-Doce Calles-SECIB, 2006.

Varela Suanzes, Joaquín, «La monarquía imposible: la Constitución de Cádiz durante el Trienio», Anuario de Historia del Derecho Español, LXVI (Madrid, 1996): 653-687.

Vargas Ugarte, Rubén, «Las negociaciones de Punchauca», Boletín del Museo Bolivariano, I/8 (Lima, abril 1929): 285-299.

Fecha de recepción: 2 de marzo de 2011

Fecha de aceptación: 15 de junio de 2011 


\section{«In order to reintegrate the Nation». Peru in the Liberal Triennium's policy of negotiation with American dissidents, 1820-1824}

Handling of the American question took a new direction during the Liberal Triennium (1820-1823). Leaders during the second period of liberalism were committed to negotiation with dissidents as a means of restoring the unity of the Spanish nation against a background of advancing insurgency. This article analyzes from the perspective of Spanish politics how the central powers explored this alternative. It presents the legislative framework and its development and explains the positions of the king, the government, the Council of State and the Cortes. It weighs its importance within the context of the other options which were considered i.e. a military solution and British mediation. The article follows the course of the negotiating process in America, with a particular focus on the viceroyalty of Peru.

Key WORDs: Liberal Triennium; American policy; negotiation; legislation; Cortes; government; Council of State; American scene; viceroyalty of Peru. 